\title{
Avaliando Propostas de Ensino Baseadas em Questões Sociocientíficas: Reflexões e Perspectivas para Ciências no Ensino Fundamental
}

\section{Evaluating Teaching Proposals Based on Socio-scientific Issues: Reflections and Perspectives for Primary Science Education}

\author{
Grégory Alves Dionor ${ }^{(1)}$ Brasil \\ Dália Melissa Conrado ${ }^{(1)}$ Brasil \\ Liziane Martins ${ }^{(1)}$ Brasil \\ Nei de Freitas Nunes-Neto Brasil
}

Atualmente, pesquisas mostram a necessidade de repensarmos a educação científica e tecnológica e refletirmos sobre um currículo voltado à politização dos estudantes, estimulando-os para tomada de decisões e ações sociopolíticas visando uma maior justiça socioambiental. Esta abordagem compõe algumas das vertentes da Educação CiênciaTecnologia-Sociedade-Ambiente (CTSA) que apontam como estratégia pedagógica o uso de Questões Sociocientíficas (QSC). Contudo, há poucos trabalhos no Brasil sobre avaliação de propostas de ensino baseadas em QSC, sobretudo no ensino fundamental. Considerando que essa avaliação contribui para uma melhor aplicação dessas propostas, aumentando as chances de êxitos na educação científica, objetivamos, em um trabalho descritivo-exploratório, analisar características dessas propostas de ensino baseadas em QSC, no nível fundamental, encontradas na literatura, com base em autores da área. Para isso, elaboramos uma ferramenta analítica, em forma de gráfico de radar, composta por eixos elencados mediante estudo da literatura pertinente. Tais eixos permitem inferir implicações para o ensino que podem ser obtidas a partir das propostas analisadas. Após análise, percebemos que as propostas didáticas vêm sido elaboradas de modo a estabelecer as relações entre os domínios CTSA, em uma abordagem contextualizada com a realidade do aluno, mobilizando as dimensões conceituais, procedimentais e atitudinais dos conteúdos. Entretanto, é necessário que a tomada de decisão consciente e justificada por argumentos, assim como o preparo e o engajamento para ações sociopolíticas, recebam uma atenção maior nessas práticas de ensino. Ademais, sugerimos questões para aperfeiçoar a própria ferramenta desenvolvida, para melhor caracterizar o ensino baseado em QSC, mesmo em diferentes níveis educacionais.

Palavras-chave: Educação científica; Educação CTSA; Propostas didáticas. 
Latest research shows the need to rethink scientific and technological education and to reflect on a curriculum aimed at student politicization, which encouraged decisionmaking and socio-political actions toward greater socio-environmental justice. This approach composes some currents of Science-Technology-Society-Environment Education (STSE) that point to the use of Socio-scientific Issues (SSI) as a pedagogical strategy. However, there are few studies in Brazil on the evaluation of SSI-based teaching proposals, especially in primary education. Considering that this evaluation contributes to a better application of these proposals, increasing the chances of success in scientific education, we aim, in a descriptive-exploratory work, to analyze characteristics of these SSI-based teaching proposals, at the primary education, found in the literature, based on authors of the field. For this, we have developed an analytical tool, in the form of a radar chart, composed of axes listed through the studying of relevant literature. Such axes allow inferring implications for teaching that can be obtained from the analyzed proposals. After analysis, we realized that the didactic proposals have been elaborated in order to establish the relationships between the STSE domains, in an approach contextualized with the student's reality, mobilizing the conceptual, procedural and attitudinal dimensions of the contents. However, it is necessary that a conscious decision-making, justified by arguments, as well as preparation and engagement for socio-political actions, receive greater attention in these teaching practices. In addition, we suggest questions to improve the tool that we developed, to better characterize SSI-based teaching, even at different educational levels.

Keywords: Science education; STSE Education; Teaching proposals.

\section{Contextualização}

Por vezes, quando um professor parabeniza uma turma em que a média de aprovação foi alta, após um teste repleto de perguntas como 'O que é isso?' ou 'Para que serve aquilo?', não exigindo dos estudantes muito mais do que uma boa capacidade de memorizar conceitos ou reproduzir funções e técnicas relativas a algum conteúdo científico, podemos refletir: será que um ensino de ciências nessa perspectiva, de fato, auxilia na formação cidadã desses estudantes para que possam compreender sua posição enquanto cidadãos, saber como agir perante os problemas socioambientais e, então, agir considerando as demandas individuais e coletivas por maior qualidade de vida nos âmbitos individual, social e ambiental?

Aikenhead (2009) aponta três grandes falhas na abordagem tradicional do ensino de ciências: "crises na matrícula dos estudantes, mitos transmitidos aos estudantes e uma falha onipresente do conteúdo de ciências da escola de ter significado para a maioria dos alunos, especialmente fora da escola" (Aikenhead, 2009, p. 3, tradução nossa). Nesse contexto, vários trabalhos (e.g.: Bencze, Carter, \& Krstovic, 2014; Conrado, 2017; Hodson, 2004; 2011; Kolstø, 2001; Martínez-Pérez, 2012; Reis, 2013; Santos, \& Mortimer, 2001; Silva, \& El-Hani, 2014) mostram a necessidade de repensarmos 
o ensino e nos voltarmos a refletir sobre um currículo que tenha como um dos seus princípios norteadores a politização dos estudantes, estimulando-os para a tomada de decisão socioambientalmente responsável, visando ações sociopolíticas para uma maior justiça socioambiental. Deste modo, contribuiríamos para a formação de cidadãos que compreendam a atividade científica; entendam as relações existentes entre as esferas da ciência, da tecnologia, da sociedade e do ambiente; e vivenciem um letramento científico ${ }^{1}$ que os prepare para pensar e executar ações de caráter sociopolítico, para o julgamento moral acerca da ciência e da tecnologia, e para a compreensão do jogo de interesses envolvidos na comunidade científica (Hodson, 2004; 2011).

Essa preocupação em problematizar e pensar criticamente a ciência, principalmente reconhecendo os impactos socioambientais em situações que envolvem a ciência e a tecnologia, ganhou força, em especial, entre as décadas de 1960 e 1970, dados os efeitos da degradação ambiental, das bombas atômicas e da guerra do Vietnã (Auler, \& Bazzo, 2001; Santos, \& Mortimer, 2002; Teixeira, 2003). Assim, surgem os estudos que seriam denominados de movimento CTS (Ciência-Tecnologia-Sociedade), e posteriormente, CTSA (com a inclusão do A, para Ambiente) ${ }^{2}$. Desde então, determinados grupos sociais, como parte da comunidade do ensino de ciências, vêm buscando, em maior ou menor comprometimento, alinhar-se com tais pressupostos teóricos, a partir da produção de materiais didáticos, da construção dos novos currículos, bem como na formação de professores (Solomon, \& Aikenhead, 1994).

Mais recentemente, no ensino de ciências, surgem preocupações acerca de como aplicar, efetivamente, o movimento ou abordagem CTSA em sala de aula, de onde surgiram desenvolvimentos sobre Questões Sociocientíficas (QSC). Entendemos QSC como controvérsias de caráter científico transdisciplinar ${ }^{3}$, polêmicas e sem necessariamente uma solução (ou seja, abertas; em inglês open-ended); que demandam a tomada de decisão, necessitando desde conhecimentos de várias disciplinas até reflexões éticas e morais acerca dos problemas envolvidos; possuem cunho social e trazem enlaces conceituais e/ou tecnológicos com os contextos científicos e a esfera ambiental; além de

1 Entendemos "letramento científico", de modo geral, como sendo as vias que possibilitem às pessoas terem conhecimento e consciência para que possam lidar com a atividade científica com confiança e competência (Saunders, \& Rennie, 2013). O significado do termo é algo que ainda se encontra em debate, com trabalhos que mostram diferentes vertentes de letramentos científicos (ver Autor, 2017; Cunha, 2017; Hand et al., 2003; Hodson, 2010; 2011; Roberts, 2007; Santos, 2007; Shamos, 1995).

2 Por nos alinharmos com a perspectiva que considera explicitamente o Ambiente (Aikenhead, 2000; 2005; Cavalcanti, Costa, \& Chrispino, 2014; Pedretti, 2003; Santos, 2008; Vilches, Gil-Pérez, \& Praia, 2011 Zoller, 1991), utilizaremos a sigla CTSA a partir daqui, para nos referir tanto a CTS quanto a CTSA.

3 Conforme Tress, Tress e Fry (2005), uma estrutura "transdisciplinar" combina disciplinas acadêmicas de paradigmas contrastantes (ciências humanas e ciências naturais, por exemplo) com as contribuições de participantes de variados grupos e organizações sociais não-acadêmicas, ou seja, uma combinação da interdisciplinaridade e a participação de outros sujeitos. Assim, todos trabalham cooperativamente para a construção de novos conhecimentos, alcançando um objetivo comum entre eles. Sobre a natureza inter- e transdisciplinar das abordagens educativas baseadas na consideração das relações CTSA das Questões Sociocientíficas, sugerimos a consulta do número 9, volume 25, da Revista Educação \& Fronteiras, cuja temática foi "Educação CiênciaTecnologia-Sociedade-Ambiente: Diálogos e Caminhos para a Inter e a Transdisciplinaridade" (e.g. Torres Merchán, Altuzarra, \& Torres, 2019). 
poderem alcançar as mídias e redes sociais (Conrado, \& Nunes-Neto, 2018a; JiménezAleixandre, \& Frederico-Agraso, 2006; Reis, \& Galvão, 2009; Sadler, 2004, Sadler, \& Murakami, 2005; Sadler, \& Donnelly, 2006).

As práticas pedagógicas e a pesquisa acadêmica, no ensino de ciências, têm dado atenção crescente às QSC. Neste sentido, vários pesquisadores têm se debruçado em investigar o uso de QSC como eixo norteador de práticas de ensino, discutindo, por exemplo: implicações nas ações dos alunos e no papel docente (Ratcliffe, 1997); a forma como os alunos realizam seus julgamentos frente a uma controvérsia (Kolstø, 2001); a importância das QSC em uma educação científica voltada para a cidadania (Ratcliffe, \& Grace, 2003); as QSC como estratégia conducente à ação sociopolítica (Reis, 2004); os padrões de raciocínio elaborados durante a tomada de decisão sociocientífica (Sadler, \& Zeidler, 2005); as dificuldades e contribuições na prática docente na abordagem de QSC (Martínez-Perez, \& Carvalho, 2012); os episódios argumentativos em atividades sociocientíficas (Mendes, \& Santos, 2013; Penha, 2012); as relações entre QSC e o pensamento complexo (Silva, 2016); os fundamentos de propostas de ensino e perspectivas para ações sociopolíticas relativas ao uso de QSC (Conrado, \& Nunes-Neto, 2018a). Entretanto, ainda é um desafio o trabalho pedagógico com QSC, sobretudo no contexto da educação fundamental, devido, entre outros, a questões como deficiências na formação inicial e continuada de professores, além de desafios pedagógicos (como falta de trabalho conjunto entre equipe docente e gestão escolar, e políticas educacionais engessadas) e curriculares (como a falta de interdisciplinaridade e a predominância de abordagens tradicionais) (Santos, Conrado, \& Nunes Neto, 2018; Martínez-Pérez, 2012; Martínez-Pérez, \& Carvalho, 2012; Mundim, \& Santos, 2012).

Portanto, considerando a importância do ensino baseado em QSC em todos os níveis educacionais, visando o estabelecimento de um processo de formação de cidadãos socioambientalmente responsáveis, ainda há algumas questões relacionadas ao tema, sobretudo no nível fundamental, demandando maior esclarecimento. Neste trabalho, consideramos o quanto determinadas características, que são consideradas relevantes, estão explicitadas nas propostas de ensino baseadas em QSC, o que vemos como uma lacuna na literatura da área, sobretudo no ensino fundamental. Assim, buscamos responder à seguinte questão geral de pesquisa: Como características essenciais para uma prática educativa baseada em QSC, elencadas por autores da área, apresentam-se explicitamente em propostas de ensino de ciências, no nível fundamental, na literatura?

Com base nesta questão, objetivamos, a partir de um trabalho descritivoexploratório, de modo preliminar, investigar como características tidas, por autores da área, como necessárias para um ensino baseado em QSC, estão articuladas em propostas de ensino encontradas na literatura, a partir da proposição de uma ferramenta analítica, representada em forma de gráfico de radar. 


\section{Procedimentos metodológicos}

Esta pesquisa, de caráter descritivo-exploratório, versa sobre alguns dos aspectos concernentes à relação entre a pesquisa sobre o Ensino de Ciências e a adoção de propostas didáticas baseadas em QSC. Por buscar entender os processos e significados, bem como os efeitos destes para o meio no qual o objeto da pesquisa se insere, esta pesquisa possui uma natureza qualitativa (Canzonieri, 2010). Ademais, trata-se de um estudo de caráter descritivo do tipo bibliográfico (Gil, 2017) visto que voltamos nossa investigação para materiais já elaborados e publicados na literatura pertinente à área, mas com um viés analítico acerca destes objetos de estudo.

As propostas analisadas foram levantadas em um estudo de revisão sistemática da literatura, realizado por nós, acerca do uso de propostas de ensino baseadas em QSC (Dionor, 2018; Dionor, et al., 2020). O corpus de análise constituiu-se de 21 intervenções didáticas norteadas por QSC, elaboradas e aplicadas em contextos de ensino das disciplinas da área de ciências naturais, nos níveis da Educação Básica (ensino fundamental), em diversos países. Buscamos por publicações contidas no período entre 2009 e 2019, que foram selecionadas em bancos de dados nacionais e internacionais escolhidos devido à relevância no cenário da pesquisa (Atas do Encontro Nacional de Pesquisa em Educação em Ciências, e Atas do Seminário Íbero-Americano CTS; SciELO, Scopus e Eric). O levantamento sistemático foi realizado por meio de uma lista exaustiva de 16 termos que se referem à QSC em português (e suas traduções em inglês e espanhol, além de variações de escrita, como plural e uso de hífen), que deveriam constar no título, no resumo e nas palavras-chave dos trabalhos. Além disso, os trabalhos, para que fossem incluídos na pesquisa, precisavam abordar discussões do campo educacional, apresentando descrições de propostas de ensino baseadas em QSC que foram aplicadas no contexto das disciplinas de ciências naturais, no Ensino Fundamental (e correspondentes em outros países). Após essa seleção, obtivemos os 21 artigos.

Todos os trabalhos selecionados (Figura 1) apresentam alguma descrição mais detalhada da proposta de ensino, como, por exemplo, o próprio contexto de aplicação, os objetivos educacionais, ou instruções de implementação, fornecendo, assim, detalhes suficientes para avaliarmos a proposta e os resultados de sua aplicação. Nós também consideramos não somente o planejamento da proposta de ensino, mas sua aplicação, uma vez que sabemos que, no âmbito educacional, há diferenças entre o esperado e o obtido e que, muitas vezes, vários aspectos e situações ocorrem durante a aplicação, surgindo pontos para refletir e aperfeiçoar a própria proposta de ensino. Dessa forma, levamos em consideração o planejamento descrito da proposta de ensino, mas também os resultados de implementação relatados no artigo, obtendo uma análise mais completa da proposta de ensino. Isso significa que não foram incluídos artigos apenas de propostas de ensino, ou que apenas discutem resultados da aplicação de uma proposta que não foi minimamente apresentada no artigo, bem como aqueles estudos que buscam apenas discutir a formação de professores, sem apresentar resultados referentes à aplicação da proposta de ensino baseada em QSC. Ressaltamos também que a análise foi realizada 
considerando apenas as informações explícitas no artigo.

\begin{tabular}{|c|c|c|c|}
\hline Código & Autores & Título & Ano \\
\hline 01 & $\begin{array}{l}\text { Arenas; Díaz; } \\
\text { Martínez-Pérez. }\end{array}$ & $\begin{array}{l}\text { Competencias ambientales em básica primaria a partir del } \\
\text { desarrollo de uma unidad didáctica sobre la controversia? } \\
\text { vivienda o humedales? }\end{array}$ & 2016 \\
\hline 02 & $\begin{array}{l}\text { Conceição; Baptista; } \\
\text { Reis. }\end{array}$ & $\begin{array}{l}\text { La contaminación de los recursos hídricos como punto de } \\
\text { partida para el activismo socio-científico }\end{array}$ & 2019 \\
\hline 03 & Culpi; Alves. & $\begin{array}{l}\text { Inserção do tema pegada hídrica no ensino de Ciências: } \\
\text { Percepções e perspectivas de mudanças a partir da sala de } \\
\text { aula }\end{array}$ & 2015 \\
\hline 04 & Eş; Öztürk. & $\begin{array}{l}\text { An Activity for Transferring the Multidimensional } \\
\text { Structure of SSI to Middle School Science Courses: I } \\
\text { Discover Myself in the Decision-Making } \\
\text { Process with SEE-STEP! }\end{array}$ & 2019 \\
\hline 05 & $\begin{array}{l}\text { Hoeg; Lemelin; } \\
\text { Bencze. }\end{array}$ & $\begin{array}{l}\text { Sociopolitical development of private school children } \\
\text { mobilising for disadvantaged others. }\end{array}$ & 2015 \\
\hline 06 & Ideland; Malmberg & $\begin{array}{l}\text { Body talk: students' identity construction } \\
\text { while discussing a socioscientific issue }\end{array}$ & 2012 \\
\hline 07 & Jones et al. & $\begin{array}{l}\text { Developing Students' Futures Thinking in Science } \\
\text { Education. }\end{array}$ & 2012 \\
\hline 08 & $\begin{array}{l}\text { Karkkainen; } \\
\text { Hartikainen-Ahia; } \\
\text { Elorinne; Hokkanen; } \\
\text { Hämeen-Anttila }\end{array}$ & $\begin{array}{l}\text { Adolescents' Learning and Experiences of Solving the Need } \\
\text { for Dietary Supplementation through Socioscientific Issue } \\
\text { (SSI) Method. }\end{array}$ & 2019 \\
\hline 09 & Kull; Zanon. & $\begin{array}{l}\text { Questões-problema propostas pelo professor em uma } \\
\text { situação de ensino investigativa: estímulo ao protagonismo } \\
\text { do estudante }\end{array}$ & 2019 \\
\hline 10 & $\begin{array}{l}\text { Martínez; Navarro; } \\
\text { Martínez-Pérez. }\end{array}$ & $\begin{array}{l}\text { La interdisciplinariedad em las cuestiones } \\
\text { sociocientíficas. }\end{array}$ & 2012 \\
\hline 11 & Moreira; Amos. & $\begin{array}{l}\text { Estudo comparativo da sustentabilidade na visão de } \\
\text { estudantes em eventos esportivos em Londres e no Rio de } \\
\text { Janeiro. }\end{array}$ & 2015 \\
\hline 12 & $\begin{array}{l}\text { Moreira; } \\
\text { Pedrancini. }\end{array}$ & $\begin{array}{l}\text { Contribuições de uma discussão sobre os aspectos políticos, } \\
\text { econômicos e éticos de uma QSC nas aulas de ciências }\end{array}$ & 2019 \\
\hline 13 & Mundim; Santos. & $\begin{array}{l}\text { Ensino de ciências no ensino fundamental por meio de } \\
\text { temas sociocientíficos: análise de uma prática pedagógica } \\
\text { com vista à superação do ensino disciplinar. }\end{array}$ & 2012 \\
\hline 14 & $\begin{array}{l}\text { Nicolaou; Evagorou; } \\
\text { Lymbouridou. }\end{array}$ & $\begin{array}{l}\text { Elementary School Students' Emotions when Exploring } \\
\text { an Authentic Socio-Scientific Issue through the Use of } \\
\text { Models. }\end{array}$ & 2015 \\
\hline
\end{tabular}

Figura 1. Trabalhos selecionados para análise (continua) 


\begin{tabular}{|c|l|l|l|}
\hline Código & Autores & Título & Ano \\
\hline 15 & $\begin{array}{l}\text { Paraskeva- } \\
\text { Hadjichambi; } \\
\text { Hadjichambis; } \\
\text { Korfiatis. }\end{array}$ & $\begin{array}{l}\text { How Students' Values are Intertwined with Decisions in a } \\
\text { Socio-scientific Issue. }\end{array}$ & 2015 \\
\hline 16 & Santos; Kato. & $\begin{array}{l}\text { Limites e possibilidades do uso de situações problemas como } \\
\text { recurso pedagógico: os temas controversos sócio científicos } \\
\text { e as relações CTSA como perspectivas para o Ensino de } \\
\text { Ciências. }\end{array}$ & 2013 \\
\hline 17 & $\begin{array}{l}\text { Santos; Conrado; } \\
\text { Nunes-Neto }\end{array}$ & $\begin{array}{l}\text { Questões sociocientíficas no ensino fundamental de ciências: } \\
\text { uma experiência com poluição de águas }\end{array}$ & 2016 \\
\hline 19 & $\begin{array}{l}\text { Santos; Rocha; } \\
\text { Chrispino. }\end{array}$ & $\begin{array}{l}\text { O uso da controvérsia controlada para abordar um tema } \\
\text { sociocientífico a partir da perspectiva Ciência, Tecnologia e } \\
\text { Sociedade (CTS) }\end{array}$ & 2019 \\
\hline 20 & Schimidt; Sutil. & $\begin{array}{l}\text { O jogo digital Minecraft como um espaço de discussão, } \\
\text { reflexão e ação a partir dos pressupostos da educação CTSA. }\end{array}$ & 2016 \\
\hline 21 & $\begin{array}{l}\text { Vissicaro; Figueirôa; } \\
\text { Araújo. }\end{array}$ & $\begin{array}{l}\text { Abordagem interdisciplinar de questões sóciocientíficas: a } \\
\text { contribuição de um projeto didático sobre a dengue para a } \\
\text { formação inicial de professores. }\end{array}$ & 2011 \\
Fundamental: o tema água em evidência. & 2016 \\
\hline
\end{tabular}

Figura 1. Trabalhos selecionados para análise (continuação)

Para realizarmos a análise destas propostas, elaboramos uma ferramenta analítica que buscasse abarcar características que, segundo alguns autores (ver abaixo), estão diretamente associadas aos resultados do uso de QSC em contextos educacionais. Tivemos como base, para delimitação destas características, o trabalho de Ratcliffe (1997), no qual a autora propõe cinco objetivos principais que devem ser observados como possíveis “implicações” (p. 4) do uso de QSC em sala de aula; sendo eles, em nossa tradução: relevância, motivação, comunicação, análise e entendimento. A partir desses cinco elementos propostos por ela, mobilizamos outros trabalhos da literatura referentes ao ensino baseado em QSC, refinando e elencando, assim, os eixos de análise que utilizamos, sendo eles:

(1) "Relevância e contextualização": visa investigar se a proposta possibilita aos alunos o desenvolvimento da capacidade de estabelecer conexões entre o conteúdo escolar (C\&T) trabalhado e a realidade socioambiental (S\&A) da temática estudada, fazendo ligações entre as esferas da ciência e da tecnologia com os contextos sociais, e as condições e os impactos ambientais. Principalmente pelo seu vínculo direto com discussões da Educação CTSA (Ciência, Tecnologia, Sociedade e Ambiente), vemos como essencial que o ensino baseado em QSC se proponha a desenvolver nos estudantes essa visão mais globalizante das relações entre esses domínios, percebendo essas relações no contexto cotidiano em que a QSC ocorre (Conrado, 2017; Martínez-Perez, \& Carvalho, 2012; MartínezPérez, \& Parga-Lozano, 2013; Pedretti, \& Nazir, 2011; Ratcliffe, 1997; Silva, 2016). 
(2) "Motivação e aplicação": a partir deste eixo, procuramos averiguar se a proposta apresentada no artigo busca mostrar a importância da educação científica e se preocupa em indicar a aplicação prática daqueles conteúdos ali mobilizados, motivando os alunos enquanto agentes ativos para usar explicitamente o conteúdo científico (ao invés de mobilizarem outros tipos de conteúdo). Deste modo, o alcance dos objetivos de aprendizagem é favorecido quando a proposta de ensino consegue vincular-se a aspectos afetivos para que os estudantes valorizem o conteúdo científico para sua aplicação no cotidiano (Conrado, 2017; Kolstø, 2001; Ratcliffe, 1997; Ratcliffe, \& Grace, 2003; Reis, 2004; Silva, 2016; Zeidler, Sadler, Simmons, \& Howes, 2005).

(3) "Argumentação e posicionamento": está relacionado ao potencial do uso da proposta baseada em QSC para que os estudantes desenvolvam sua capacidade de avaliar e construir argumentos, tornando seus pontos de vista e opiniões mais coerentes e melhor qualificados, com base em conteúdos. Aqui há também um olhar para a tomada de decisão, ou seja, se a proposta, em algum momento, se atenta à necessidade de que os estudantes assumam posicionamentos de forma crítica, proativa e consciente, isto é, não apenas analisando a situação com base nos conteúdos, mas tomando decisões sobre caminhos e contribuições possíveis para a resolução da QSC (Conrado, \& Nunes-Neto, 2015; Jiménez-Aleixandre, \& Pereiro-Munhoz, 2002; Jiménez-Aleixandre, Rodríguez, \& Duschl, 2000; Mendes, \& Santos, 2013; Mendonça, \& Justi, 2013; Penha, 2012; Ratcliffe, 1997; Silva, 2016).

(4) "Análise e resolução de problemas": procuramos, a partir deste eixo, verificar se a proposta em questão busca trabalhar com os estudantes a análise crítica das QSC abordadas, visando a proposição de soluções e mobilização dos sujeitos para ações sociopolíticas individuais e/ou coletivas, isto é, execução de ação informada a partir da análise de diferentes pontos de vista e soluções para os problemas relacionados às QSC (Bencze, Carter, \& Krstovic, 2014; Bencze et al., 2018; Conrado, 2017; Hodson, 2011; Kolstø, 2001; Martínez-Pérez, Carvalho, Lopes, Carnio, \& Vargas, 2011; Ratcliffe, 1997; Sadler, 2004; Sadler, \& Zeidler, 2005; Silva, 2016).

(5) "Compreensão e mobilização de conteúdos": buscamos avaliar se a intervenção didática mobiliza explicitamente outras dimensões dos conteúdos para além da conceitual; se, no decorrer das atividades estabelecidas, as dimensões procedimentais e atitudinais vinculadas aos conteúdos desenvolvidos também são mobilizadas explícita e sistematicamente, indicando a importância dessas duas dimensões dos conteúdos, ao lidar com QSC (Conrado, \& Nunes-Neto, 2018b; Coll, Pozo, Sarabia, \& Valls, 1992; Conrado, 2017; Conrado, \& Nunes-Neto, 2015; Oulton, Dillon, \& Grace, 2004; Ratcliffe, 1997; Sadler, \& Zeidler, 2004; Silva, 2016; Zabala, 1998).

É importante ressaltar que, ao nosso ver, as características descritas nos eixos coexistem naturalmente nos processos de ensino e aprendizagem relacionados ao ensino baseado em QSC. Esta categorização que propomos surge como uma necessidade de organização e sistematização destas características para fins didáticos e de análise nesta pesquisa, de modo a melhor caracterizar as propostas avaliadas. Em outras palavras, a decisão por separar tais características em eixos distintos é uma decisão metodológica, 
mas reconhecemos que estas, em contextos reais de aplicação, acabam por se apresentarem de modo imbricado, entrelaçado. Além disso, podemos refletir a relevância desses 5 eixos para uma boa qualidade da proposta de ensino baseado em QSC, sobretudo, considerando que: o eixo 1 é um requisito para sensibilizar o estudante, ao ter uma visão geral das influências mútuas de CT no contexto SA da QSC; o eixo 2 é um requisito para o estudante valorizar o conteúdo científico escolar, ao perceber a importância deste conteúdo na vida cotidiana; o eixo 3 é um requisito para o uso do conhecimento científico escolar no posicionamento esclarecido e na decisão justificada do estudante sobre a QSC estudada; o eixo 4 é fundamental para desenvolver a capacidade de análise e de ação sobre a QSC estudada; e, por fim, o eixo 5 é uma condição de possibilidade para o desenvolvimento adequado dos outros eixos, visto que sensibilidade, afetividade, valorização, posicionamento, criticidade, entre outros, são virtudes necessárias em todo o processo de mobilização dos conteúdos escolares, para um melhor entendimento desses conteúdos em sua prática, isto é, aplicado à convivência, permitindo, assim, o desenvolvimento de habilidades intrapessoais (ex. autoconhecimento e capacidade de lidar consigo), interpessoais (ex. comunicação e consideração com o outro) e de identidade e pertencimento (ex. perceber seu papel na sociedade), no processo de aprendizagem dos conteúdos escolares (Conrado, 2017). Nesse sentido, todos os 5 eixos estão conectados: ao sensibilizar o estudante sobre as relações entre os domínios CTSA no contexto da QSC (eixo 1), o estudante poderá melhor visualizar e valorizar o conteúdo científico escolar na realidade (eixo 2), o que favorecerá o uso desse conteúdo para justificar seu posicionamento e as decisões em relação à QSC estudada (eixo 3), durante o processo de avaliação de melhores caminhos e organização de melhores modos de ação (eixo 4), com isso, reconhecendo e explicitando as dimensões CPA dos conteúdos científicos (eixo 5).

Para representar, visualmente, a análise das propostas didáticas, sistematizamos os critérios acima estabelecidos em uma ferramenta analítica em forma de gráfico radar (Figura 2). Um Gráfico radar pode ser entendido como uma forma representativa circular com eixos radiais que apresentam visualmente os resultados das análises realizadas a partir de eixos graduados em níveis (Costa, 2005; Drees, 2007). Deste modo, podemos observar graficamente, a partir das conformações dos gráficos, as características das propostas nos cinco eixos, possibilitando comparações iniciais dos diferentes trabalhos. 


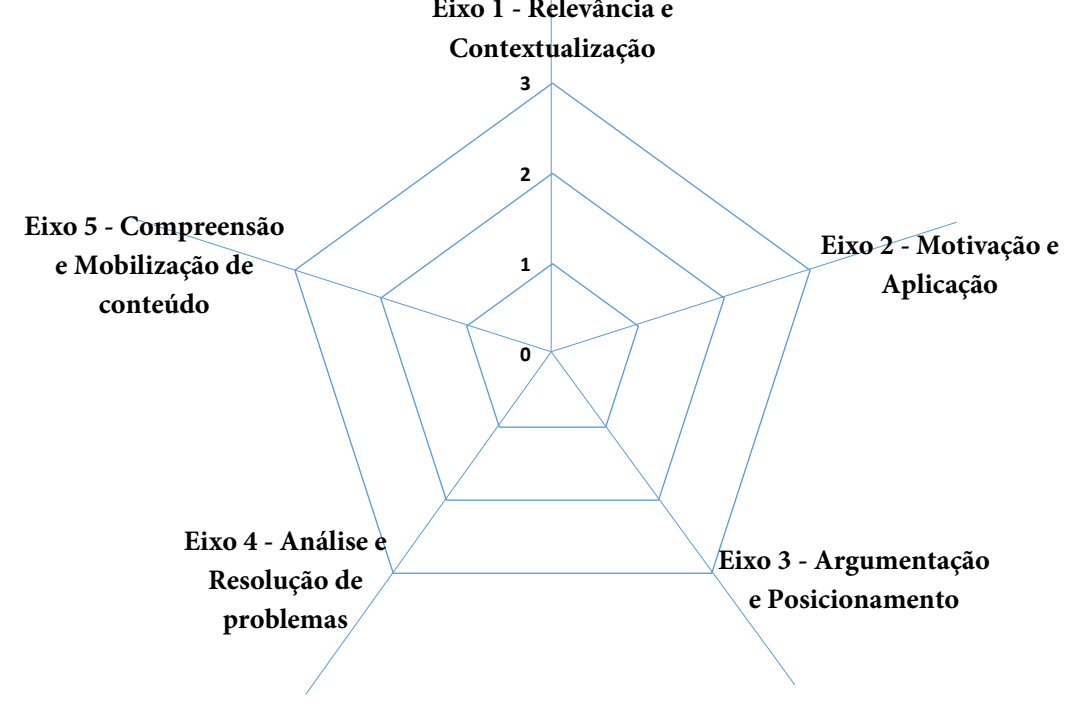

Figura 2. Ferramenta analítica construída para a análise, composta pelos cinco eixos analíticos elaborados por nós, com base em literatura pertinente

Na ferramenta acima, vemos a indicação dos cinco eixos descritos anteriormente, sendo que, para cada eixo, a proposta foi avaliada com os seguintes níveis de sofisticação ${ }^{4}$ : "Abordagem Simplificada" (1), "Abordagem Intermediária" (2) e "Abordagem Ampliada" (3); no caso de a proposta em análise não apresentar algum dos eixos, é atribuído o valor (0) "Não se aplica". Entretanto, definir os indicadores que diferenciam e classificam os níveis é tido como um dos aspectos mais problemáticos na construção de gráficos radar (Ornstein, 1989; Reske-Filho, \& Rocchi, 2008). Na tentativa de superar tal limitação, nossos níveis de sofisticação - Abordagem Simplificada, Abordagem Intermediária e Abordagem Ampliada - foram determinados a partir do estudo da literatura mobilizada na construção de cada eixo. No quadro a seguir (Figura 3), detalhamos como os eixos se apresentam em cada nível.

\begin{tabular}{|l|l|l|l|}
\hline & $\begin{array}{l}\text { Abordagem } \\
\text { Simplificada (1) }\end{array}$ & $\begin{array}{l}\text { Abordagem Intermediária } \\
(2)\end{array}$ & $\begin{array}{l}\text { Abordagem Ampliada } \\
(3)\end{array}$ \\
\hline $\begin{array}{l}\text { EIXO 1 - } \\
\text { Relevância e } \\
\text { contextualização }\end{array}$ & $\begin{array}{l}\text { Explicita a existência } \\
\text { de relações entre C\&T } \\
\text { e suas ligações com a } \\
\text { esfera social (S). }\end{array}$ & $\begin{array}{l}\text { Abrange o contexto } \\
\text { socioambiental (SA) das } \\
\text { relações entre C\&T, sem } \\
\text { relacionar a QSC com o } \\
\text { cotidiano do estudante. }\end{array}$ & $\begin{array}{l}\text { Reconhece as mútuas } \\
\text { relações entre os } \\
\text { domínios CTSA e suas } \\
\text { correlações da QSC } \\
\text { com o cotidiano do } \\
\text { estudante. }\end{array}$ \\
\hline
\end{tabular}

Figura 3. Descrição dos eixos por nível de sofisticação, sendo os estágios determinados a partir de estudo da literatura (continua)

4 Entendemos como 'níveis de sofisticação' três diferentes graus de abrangência para cada eixo. Desse modo, para cada eixo, atribuímos três possíveis categorias para conseguirmos avaliar o aprofundamento de cada proposta de ensino, sendo que consideramos o nível 1 uma abordagem simplificada sobre aquele eixo, o nível 2 uma abordagem intermediária, e o nível 3 uma abordagem ampliada relacionada ao conteúdo do eixo correspondente. 


\begin{tabular}{|c|c|c|c|}
\hline & $\begin{array}{l}\text { Abordagem } \\
\text { Simplificada (1) }\end{array}$ & $\begin{array}{l}\text { Abordagem Intermediária } \\
\text { (2) }\end{array}$ & $\begin{array}{l}\text { Abordagem Ampliada } \\
(3)\end{array}$ \\
\hline $\begin{array}{l}\text { EIXO } 2 \text { - } \\
\text { Motivação e } \\
\text { aplicação }\end{array}$ & $\begin{array}{l}\text { Permite reconhecer } \\
\text { a importância da } \\
\text { Educação Científica } \\
\text { para a Sociedade. }\end{array}$ & $\begin{array}{l}\text { Mobiliza conteúdos da } \\
\text { Educação Científica no } \\
\text { contexto das práticas } \\
\text { sociais, de modo alheio/ } \\
\text { distante da realidade dos } \\
\text { estudantes. }\end{array}$ & $\begin{array}{l}\text { Explicita o valor dos } \\
\text { conteúdos da Educação } \\
\text { Científica para } \\
\text { aplicação no contexto } \\
\text { social do próprio } \\
\text { estudante. } \\
\end{array}$ \\
\hline $\begin{array}{l}\text { EIXO } 3 \text { - } \\
\text { Argumentação e } \\
\text { posicionamento }\end{array}$ & $\begin{array}{l}\text { Apresenta diferentes } \\
\text { pontos de vista e } \\
\text { opiniões acerca da } \\
\text { QSC tratada, sem } \\
\text { demandar argumentos } \\
\text { qualificados ou a } \\
\text { tomada de decisão. }\end{array}$ & $\begin{array}{l}\text { Incita os estudantes } \\
\text { a debaterem e se } \\
\text { posicionarem, } \\
\text { considerando, os diferentes } \\
\text { pontos de vista. }\end{array}$ & $\begin{array}{l}\text { Estimula os estudantes } \\
\text { à apresentarem os } \\
\text { diferentes pontos de } \\
\text { vista envolvidos na } \\
\text { QSC, tomando decisão } \\
\text { consciente e justificada } \\
\text { com argumentos } \\
\text { qualificados sobre sua } \\
\text { decisão. }\end{array}$ \\
\hline $\begin{array}{l}\text { EIXO } 4 \text { - Análise } \\
\text { e resolução de } \\
\text { problemas }\end{array}$ & $\begin{array}{l}\text { Suscita uma análise } \\
\text { da controvérsia em } \\
\text { questão. }\end{array}$ & $\begin{array}{l}\text { Busca, através de uma } \\
\text { análise crítica, a proposição } \\
\text { de possíveis resoluções para } \\
\text { o problema abordado. }\end{array}$ & $\begin{array}{l}\text { Após a proposição de } \\
\text { possíveis soluções, } \\
\text { com base em uma } \\
\text { análise crítica, mobiliza } \\
\text { os alunos para ações } \\
\text { sociopolíticas em } \\
\text { nível individual e/ou } \\
\text { coletivo. }\end{array}$ \\
\hline $\begin{array}{l}\text { EIXO } 5 \text { - } \\
\text { Compreensão e } \\
\text { mobilização de } \\
\text { conteúdo }\end{array}$ & $\begin{array}{l}\text { Predomina a } \\
\text { mobilização dos } \\
\text { conteúdos através da } \\
\text { dimensão conceitual. }\end{array}$ & $\begin{array}{l}\text { Explicita, além da } \\
\text { dimensão conceitual, a } \\
\text { dimensão procedimental } \\
\text { ou a dimensão atitudinal } \\
\text { dos conteúdos. }\end{array}$ & $\begin{array}{l}\text { Mobiliza explicitamente } \\
\text { as três principais } \\
\text { dimensões do } \\
\text { conteúdo - conceitual, } \\
\text { procedimental e } \\
\text { atitudinal. }\end{array}$ \\
\hline
\end{tabular}

Figura 3. Descrição dos eixos por nível de sofisticação, sendo os estágios determinados a partir de estudo da literatura (continuação)

A ferramenta analítica foi elaborada por meio dos softwares Microsoft PowerPoint $^{\circledR}$, para a elaboração gráfica da ferramenta, e Microsoft Excel ${ }^{\circledR}$, para inserção e gerenciamento dos dados numéricos correspondentes às avaliações dos eixos. A ferramenta, depois de construída, foi discutida entre os pesquisadores envolvidos na pesquisa. Cada uma das 21 propostas foi analisada a partir desta ferramenta de modo a nos possibilitar inferir algumas implicações destas para o ensino baseado em QSC. É importante ressaltar que esta ferramenta poderá passar, a posteriori, por outras fases de avaliação e aprimoramento; ou seja, reconhecemos que este instrumento analítico ainda pode carecer de novas contribuições e melhoramentos, mas, para esta pesquisa, ele é capaz de nos auxiliar a alcançar os objetivos que esperamos. 


\section{Resultados e Discussão}

No processo de análise, procuramos, na descrição das propostas relatadas nos trabalhos e sua aplicação, elementos que nos permitissem classificá-las segundo os níveis dos eixos elencados na ferramenta analítica descrita na seção anterior.

Nesse sentido, como forma de sistematizar as discussões, apresentamos, na Tabela 1, a caracterização geral das propostas nos eixos e níveis de sofisticação.

Tabela 1. Distribuição do número de propostas nos eixos e por níveis de sofisticação

\begin{tabular}{llllll}
\hline & Eixo 1 & Eixo 2 & Eixo 3 & Eixo 4 & Eixo 5 \\
\hline N1 & 04 Trabalhos & 04 Trabalhos & 06 Trabalhos & 11 Trabalhos & 01 Trabalho \\
\hline N2 & 02 Trabalhos & 06 Trabalhos & 11 Trabalhos & 04 Trabalhos & 05 Trabalhos \\
\hline N3 & 13 Trabalhos & 08 Trabalhos & 02 Trabalhos & 04 Trabalhos & 15 Trabalhos \\
\hline NA & 02 Trabalhos & 03 Trabalhos & 02 Trabalhos & 02 Trabalhos & 0 Trabalho \\
\hline
\end{tabular}

Legenda: N: Nível; NA: Não se Aplica

Considerando a ferramenta desenvolvida (Figura 3), exceto pelo trabalho n. 20, observamos que todas as propostas contêm, em algum grau de abrangência, a presença de ao menos quatro dos cinco critérios estabelecidos nos eixos que comportam as principais características do ensino baseado em QSC (Figuras 4, 5, 6, mais abaixo). A seguir, discutiremos resultados gerais obtidos a partir de cada Eixo da ferramenta, para depois finalizarmos com uma avaliação geral, considerando os cinco eixos conjuntamente.

\section{Eixo 1 - Relevância e contextualização}

Como podemos perceber, a maioria das propostas enquadram-se no nível 3 (13 propostas), no qual as atividades desenvolvidas buscam mostrar os impactos socioambientais da relação C\&T. Por exemplo, no trabalho 02 , os estudantes, em uma saída de campo, identificaram sinais de contaminação de um riacho, "discutindo amplamente os temas de ciências e de tecnologia que estão na base do problema e as possíveis soluções, bem como as responsabilidades individual, coletiva e política associadas" (p. 1502-8, tradução nossa). O trabalho 01 também segue esta perspectiva da Educação CTSA, ao procurar, "na unidade didática de reconhecimento da problemática ambiental" (p. 710, tradução nossa), identificar causas, estabelecer consequências e determinar os atores envolvidos nos conflitos de interesses relacionados à problemática ambiental em questão (a construção de um conjunto residencial em uma zona úmida da cidade, região semelhante ao pantanal brasileiro). Nesse trabalho, os estudantes expuseram "diferentes aspectos do problema, como a contaminação das áreas úmidas, a deterioração do habitat natural que afeta animais endêmicos desse ecossistema, o impacto que as construções geram nos reservatórios de água da cidade de Bogotá" (p. 716), além de identificarem "interesses econômicos, políticos e sociais que existem por trás do problema ambiental" (p. 716). O trabalho 11, que aborda a sustentabilidade de eventos esportivos, indicou que "cada grupo desenvolveu um dos aspectos levantados por eles 
em relação às dimensões políticas, sociais, econômicos, científicas e ambientais” (p. 5). Já no trabalho 16, algumas questões norteadoras muito gerais (p. ex.: "o avanço da tecnologia para a nanotecnologia e seu uso são importantes para a humanidade? Ou trazem riscos para o ambiente e para a espécie humana? Devemos investir nessas pesquisas?", p. 3-4), podem ter dificultado o trabalho de percepção da QSC estudada com o cotidiano do estudante (p. ex.: "Um aluno estabelece uma relação entre a tecnologia e a ciência, apesar de não deixar explícita como ocorre essa ligação.”, p. 5). Situação semelhante pode ser visualizada no trabalho 09, como no trecho: "Exibir três animações: "Rios Voadores" e trechos específicos extraídos da animação "Wall-e"; (...) - Quais as funções das folhas nestes vídeos? - Como é cada ambiente mostrado? - Quais seriam suas sensações em cada ambiente? - Como serão as plantas desse ambiente?" (p. 3); esses são exemplos de problematizações que muitas vezes não permitem a aproximação direta das relações CTSA da QSC com o contexto diário dos estudantes. Nesse caso, perguntas mais diretas poderiam estimular essa associação mais direta.

Os trabalhos 8 e 19 foram os únicos em que classificamos como 'não se aplica', uma vez que eles não explicitam relações CTS ou CTSA na discussão das QSC com os estudantes. O primeiro discutiu o uso de suplementos nutricionais, sem problematizar as relações CTSA, enquanto o segundo, apesar de enunciar o tema 'biotecnologia e fisiologia humana', durante a aplicação da sequência didática, foram discutidos apenas problemas estruturais da escola, sem explorar as relações CTSA das temáticas. A relação entre a Educação CTSA e o uso de QSC no ensino se dá de modo estreito, sendo que alguns autores consideram o ensino baseado em QSC como um meio para alcançar a concretização dos objetivos propostos na Educação CTSA (e.g. Martínez-Pérez; Parga-Lozano, 2013; Pedretti, 2003), sendo que o ponto de diferenciação, conforme alguns autores, reside no fato de que o ensino baseado em QSC abarca uma ênfase no desenvolvimento tanto epistemológico quanto psicológico dos estudantes, bem como na promoção do aprimoramento do caráter e de virtudes (Pedretti, \& Nazir, 2011; Zeidler et al., 2005), existindo entre elas (QSC e CTSA) uma relação de complementariedade objetiva específica (ver Silva, 2016).

Já os artigos 5, 12, 13, 18 não explicitam a dimensão ambiental na discussão das QSC com os estudantes, por priorizarem a discussão de relações CTS, sobretudo em uma perspectiva humanizadora. Dentre as vertentes de Educação CTSA (sensu Pedretti, \& Nazir, 2011) nas quais as QSC figuram normalmente como estratégia viabilizadora (Raciocínio lógico, Centrada em valores, Sociocultural e Justiça socioambiental), as QSC podem ser utilizadas para contribuir no alcance dos mais variados fins - formação para cidadania, responsabilidade cívica, tomada de decisão, realização cultural e intelectual, resolução de problemas e emancipação (Pedretti, \& Nazir, 2011) - a depender dos objetivos que se esperam ser alcançados. Deste modo, a partir do contexto e dos fins para os quais as QSC são utilizadas, elas podem auxiliar na promoção de vertentes da Educação CTSA de modo interligado à realidade dos estudantes, e envolvendo explicitamente a dimensão ambiental, preparando-os para compreender e agir frente à 
Ciência e à Tecnologia aos quais têm acesso, à Sociedade em que vivem e ao Ambiente ao qual fazem parte.

\section{Eixo 2 - Motivação e aplicação}

Aqui, as propostas foram classificadas principalmente nos níveis 3 (8 propostas) e 2 (6 propostas). Dentre os trabalhos analisados que apresentam esse eixo desenvolvido de forma bem ampliada, podemos citar a proposta do artigo 14 em que, não só abordou em sala a problemática da proliferação excessiva de mosquitos na região, como também levou os alunos para o lago da cidade onde puderam reconhecer melhor o local e observá-lo com um olhar mais analítico (coletando dados) para a situação em questão ("Durante a visita, eles (...) tiraram fotos do lago e seus arredores e investigaram que tipos de organismos vivem e em torno do lago de sal. Depois de voltar para a aula, (...) o professor sugeriu que relatassem suas perguntas em seus cadernos e pesquisassem on-line (...)" p. 245, tradução nossa). No artigo 3, os autores propõem, como parte de sua intervenção didática, uma atividade na qual os alunos precisam encontrar matérias e notícias em revistas e jornais locais relacionadas com a QSC em questão (pegada hídrica). Os autores justificam esta atividade pois, "Conhecer o que se passa em sua comunidade é condição fundamental na perspectiva de alterar a visão sobre o mundo, geralmente acrítica, desinformada e fundamentada em 'achismos' [...]” (p. 27). Nesse caso, os estudantes puderam compreender "que, de fato, ocorre desperdício de água em diferentes situações cotidianas", ao trabalharem conteúdos científicos no processo de análise do uso da água.

Essa perspectiva de que o ensino estimule os alunos a perceberem a aplicação (e aplicarem) dos conteúdos vistos na educação científica nos contextos de sua realidade aproxima-se de uma das visões - a Visão II - da literacia científica ${ }^{5}$ (Roberts, 2007), na qual o aluno, além de entender a atividade científica, percebe as influências dela no meio social e como a tomada de decisão acerca de aspectos da relação C \& T precisa de reflexões de cunho moral, político, econômico, cultural etc., aproximando-se mais da abordagem de uma "Educação Científica Progressista" (Sadler, \& Zeidler, 2009, p. 918, tradução nossa). Nesta abordagem, o enfoque está em preparar os alunos para serem cidadãos que consigam aplicar os conhecimentos científicos na vida real, capazes de refletir e se posicionar frente a eles, de modo integrado a outros aspectos da vida em sociedade; dentre os meios para se alcançar esses objetivos, está o uso de QSC como norteadoras de propostas de ensino (Penha, 2012).

É importante que a relação entre conteúdo e realidade também permita que o estudante possa analisar relações em vários níveis, como na proposta relatada no artigo 5, na qual os estudantes de escolas particulares e famílias mais abastadas foram conduzidos a refletir que objetos e situações relativamente comuns do cotidiano deles (como bola, chocolate, bananas ou até notícias sobre guerras nas mídias) envolvem

$5 \mathrm{Na}$ Visão I, o foco está no aprendizado de conceitos e procedimentos utilizados na construção do conhecimento científico, sem promover muitas correlações dessa esfera com outras, como a social e a ambiental (Roberts, 2007). 
crianças de outros países em situações de trabalho escravo. Deste modo, eles têm a chance de se perceberem como cidadãos globais e que suas decisões refletem não só na sua rotina diária, mas impacta todo o mundo. Contudo, essa proposta não explicitou que conteúdos das ciências naturais foram diretamente mobilizados pelos estudantes, por isso, a proposta foi classificada como "Não se aplica" para esse eixo. Situação semelhante ocorreu com o artigo 12 que, apesar do tema fosfoetanolamina estar diretamente conectado com aspectos da ciência, "reconhece-se que a complexidade do referido caso não foi explorada como um todo neste episódio de ensino como, por exemplo, a natureza do conhecimento científico" (p. 5), favorecendo, sobretudo, "dimensões sociais, políticas e econômicas que abarcam a QSC” (p. 5). Já o artigo 21 tem foco sobre a formação de professores dos anos iniciais, por isso, não aprofunda na discussão da proposta de ensino nem em sua aplicação, faltando elementos para discutirmos esse eixo na proposta apresentada.

No artigo 11, não há indicação, de modo explícito, de quais conteúdos foram mobilizados pelos estudantes, na discussão da QSC; apenas aponta, de modo geral, sobre áreas do conhecimento que os estudantes trabalharam, sem relacionar com o cotidiano (ex.: "nas narrativas dos estudantes foi a da radioatividade, numa perspectiva baseada em argumentos ambientais, ecológicos e científicos”, p. 5). Já no artigo 9, os estudantes discutem "processos de proposição de hipóteses, obtenção, registro e análise dos dados" (p. 4), mas percebemos que as discussões não estão explicitamente conectadas com práticas sociais, como no exemplo de fragmento:

Pergunta: Qual a importância das folhas para a planta e o ambiente? (Professora) Resposta: As folhas são muito importantes, pois são elas que possuem a clorofila e realizam a fotossíntese. Tem folhas pequenas e grandes, de vários tamanhos. As folhas são responsáveis pela transpiração, gutação e respiração da planta, elas são verdes e tem muitas presentes em cada árvore. Elas também deixam o ar limpo e bom, pois liberam gás oxigênio com a fotossíntese. (Grupo 5) (artigo 9, p. 6).

Ainda, seis artigos $(1,7,8,10,15,16)$, apesar de permitirem a mobilização do conteúdo científico, não explicitam a relação deste com o contexto social direto dos estudantes, como, por exemplo, nos fragmentos a seguir: "ajudou a focalizar discussões em grupo sobre a ciência subjacente (...) novas tecnologias, como modificação genética; resultados de pesquisas futuras, como a identificação de genes úteis" (artigo 7, p. 711, tradução nossa); - "a floresta é um grande ecossistema com muitas plantas, animais e outros organismos. O ciclo de vida de todos esses organismos será destruído " S8 - Raciocínio ambiental. - "a floresta fornece oxigênio para a cidade e é importante para a saúde das pessoas”, S9 - Raciocínio social. (artigo 15, p. 504 tradução nossa) "considerando o conhecimento científico como fundamento que justifica os argumentos construídos" (artigo 16, p. 7); "Eles também conheciam as classes de vitaminas, ou seja, que existem vitaminas hidrossolúveis e lipossolúveis” (artigo 8, p. 169). Os conteúdos específicos das ciências, quando abordados no ensino baseado em QSC, estão atrelados a aspectos sociais, políticos, éticos presentes na realidade dos estudantes, para que estes 
possam perceber a relevância da ciência nas práticas sociais (Conrado, 2017; MartínezPérez, \& Carvalho, 2012).

\section{Eixo 3 - Argumentação e posicionamento}

Considerando o desenvolvimento da capacidade para perceber diferentes pontos de vista e mobilizar conteúdos para justificar posicionamentos em relação à QSC, o nível com maior incidência dos trabalhos analisados foi o nível 2 (11 propostas). Por exemplo, no artigo 10, durante a atividade de reflexão final, os alunos precisavam, após analisarem todos os argumentos prós e contras sobre as situações em estudo, assumir um posicionamento, como nos exemplos: "o estudante deve assumir uma posição a favor ou contra a rega de hortaliças com água do rio Bogotá" (p. 5, tradução nossa); "o estudante deve assumir uma posição a favor ou contra a legalização da droga" (p. 6, tradução nossa). No artigo 7, os estudantes perceberam que "As políticas de compra de lojas influenciam o que está disponível" (p. 694), fazendo, então, "decisões pessoais" (p. 695), e discutindo "Quais são as causas subjacentes a essas alterações?" (p. 695); "Quem se beneficia? Quem perde?” (p. 694). Ainda, no texto 18, em que os estudantes assumiam papéis para discutir uma controvérsia sobre agrotóxicos, relatou-se que "Durante a atividade foi solicitado que os alunos se posicionassem em relação a essas três propostas (....) a decisão de se usar uma nova tecnologia às suas vantagens e desvantagens (...) quais atores sociais deveriam decidir os assuntos científicos do país" (p. 3), havendo, então, propostas prontas para que os estudantes apenas se posicionassem. Já na proposta 11, que tratava sobre os eventos megaesportivos, os alunos precisavam argumentar sobre questões relacionadas à sustentabilidade que estivessem ligadas aos eventos, mas não foi solicitado que os alunos se posicionassem (ex.: "Evidências a favor da sustentabilidade / Evidências contra a sustentabilidade" p. 5). A importância do desenvolvimento da capacidade argumentativa no Ensino de Ciências reside numa série de razões tais como a imanência da argumentação no processo da formação cidadã, pois isto implica aprender a argumentar e defender seus posicionamentos frente aos problemas sociais (Santos, \& Schnetzler, 1997); além da visão de que a argumentação é ponto central de uma educação científica que prepare os estudantes para avaliar e lidar com os impactos da ciência no cotidiano (Mendes, 2012; Newton, Driver, \& Osborne, 1999); além de que, no processo argumentativo, os alunos acabam por trabalhar a capacidade de articulação entre a esfera científica e social, apropriando-se devidamente de noções e conceitos (Lewis, \& Leach, 2006; Mendonça, \& Justi, 2013).

Quanto à tomada de decisão, precisamos ter em mente que os problemas que enfrentamos enquanto cidadãos vão além de opções objetivas, dicotômicas ou simples escolhas como A ou B, na qual a resposta está certa ou errada (modelo ainda muito usado nos problemas escolares); as escolhas feitas no processo de tomada de decisão são complexas, subjetivas, exigindo dos alunos (formando-se para atuarem como cidadãos) julgamentos críticos e políticos, para que os discentes possam perceber como suas decisões influenciam na manutenção de ou na mudança para uma sociedade 
mais socioambientalmente responsável ou não (Conrado, 2017; Santos, \& Mortimer, 2001; Silva, \& El-Hani, 2014). Podemos exemplificar, no artigo 4, quando o estudante declara que "Gostei da atividade porque tive a chance de me expressar em uma questão controversa, tive uma discussão com meus amigos e tomamos nossas decisões pessoais. (S24)" (p. 14, tradução nossa). E, no artigo 15: "Cada aluno mencionou vários critérios (...) e, em seguida, explicou a decisão com argumentos elaborados em uma pergunta aberta." (p. 500, tradução nossa); "os alunos foram capazes de perceber que a QSC (...) envolvia várias vantagens e desvantagens e com muitos interesses conflitantes e várias soluções” (p. 508, tradução nossa). Portanto, tomar decisões está para além do posicionamento, uma vez que o estudante se compromete mais firmemente: "A tomada de decisão estaria relacionada tanto à mudança atitudinal dos estudantes quanto à construção de determinados valores que lhes possibilitem um comportamento e um agir mais consistente" (Martínez-Pérez, 2012, p. 200), sugerindo, assim, uma análise prévia pormenorizada, que fortalecerá as justificativas para a decisão (Santos, Lopes, Carnio, Carvalho, \& Carvalho., 2011).

A necessidade de uma formação para a cidadania que prepare os sujeitos para a tomada de decisão, é reforçada por vários interlocutores do Movimento CTSA (Teixeira, 2003), porém, apenas duas (4 e 15) das propostas analisadas alinham-se/aproximam-se deste objetivo, o que pode ser considerado algo preocupante, visto que a capacidade de tomar uma decisão e argumentar acerca dela está, ao nosso ver, relacionada ao exercício da cidadania. Os artigos 9 e 20 não indicaram se houve a percepção de diferentes pontos de vista sobre a QSC, pelos estudantes. Isso pode prejudicar o desenvolvimento do próximo eixo, pois, uma vez que o estudante não percebe os diferentes pontos de vista, a análise da questão torna-se limitada e quando não se posiciona, pode não desenvolver o potencial para agir, em alguma instância, para resolver o problema.

\section{Eixo 4 - Análise e resolução de problemas}

Neste eixo, diferentemente dos resultados anteriores, o nível 1 foi o que apresentou a maioria das avaliações (11 propostas), ou seja, nestes trabalhos apenas é proposto uma análise da controvérsia sociocientífica central, sem que os alunos precisem propor possíveis soluções (nível 2), e sem estimulá-los para a realização de ações sociopolíticas (nível 3).

Na proposta relatada no artigo 16, propõe-se a realização de um debate norteado por um texto inicial da problematização. O texto utilizado indica que "Fica evidente a percepção da polêmica gerada pela situação problema colocada" (p. 6). Contudo, o texto não indica a proposição de soluções pelos estudantes sobre a controvérsia. Já no texto 18, que avaliou concepções CTS de estudantes ao debaterem sobre agrotóxicos, os autores afirmam que "os alunos se valeram de argumentos científicos para justificar o posicionamento de seus atores sociais durante a controvérsia" (p. 6), porém, apesar de discutirem a controvérsia, o texto não indica se próprios estudantes buscaram ou propuseram soluções em relação à QSC estudada. 
Em um ensino baseado em QSC, busca-se também que os estudantes possam avaliar e assumir a responsabilidade pelas decisões tomadas e ações realizadas, principalmente para que os alunos possam reconhecer as problemáticas como uma preocupação pessoal, logo, assumindo responsabilidade por tal (Santos, \& Mortimer, 2001).

No artigo 20, os autores, em sua proposta didática acerca da problemática envolvendo a dengue, propuseram que os alunos realizassem uma campanha para combate à dengue, com a confecção de panfletos informativos, a montagem de um mural expositivo na escola e explicações orais nas turmas do colégio. Contudo, durante a aplicação, foi percebido que "nem todos os registros apresentam reflexões. Alguns apenas trocam os culpados, sem perceber a relação entre os diferentes elementos" (p. 1604). Nesse caso, apesar da intervenção indicar que "favoreceu a percepção de que a questão da água é muito mais complexa do que usualmente se divulga na mídia" (p. 1604), não foi discutida a busca por possíveis soluções em relação à dengue, ocorrendo apenas um direcionamento para que se desenvolvessem importantes trabalhos coletivos de divulgação sobre o tema, envolvendo a comunidade escolar. No artigo 13, não se deixou clara a discussão com os estudantes sobre a controvérsia envolvida com o tema; assim, provavelmente por conta dos problemas na aplicação da proposta, como relatado no artigo ("As aulas dessa etapa ocorreram com bastante dificuldade (...). Essas situações atrapalharam o andamento das aulas, provocando mudanças drásticas no planejamento inicial e dificultando a realização de atividades, principalmente aquelas relacionadas aos debates e à exposição de ideias", p. 795), não houve discussão de controvérsias que envolvem a QSC, por exemplo, se houvesse indicação de diferentes pontos de vista sobre o significado de 'alimentação saudável'.

Portanto, reconhecemos que a realização de um ensino baseado em QSC que vise, particularmente, à ação sociopolítica alinhada à justiça socioambiental é uma tarefa complexa, que traz uma série de demandas, principalmente aos docentes, como a necessidade de acreditar fortemente no potencial dessas atividades para o empoderamento dos estudantes, conhecer não só o arcabouço pedagógico necessário para realizar essas atividades, mas, também, compreender as relações entre as esferas da ciência, da tecnologia, da sociedade e do ambiente, contextualizando-as com a realidade na qual os alunos estão imersos; além do empenho na tarefa de agir de modo a mudar ou preservar estruturas sociais estabelecidas, sendo este ponto (mudar ou preservar) um dos elementos controversos a serem discutidos (Hodson, 2011; Reis, 2014).

Um movimento que não só desponta como possibilidade de materialização da Educação CTSA, mas que pode ser realizado de modo alinhado às QSC é o de Future Studies $^{6}$ (também chamado de Futures Thinking). O artigo 7 buscou desenvolver uma proposta didática que visava justamente mostrar essa articulação entre QSC, Future Thinking e Educação CTSA. Nesta proposta, os autores trazem uma abordagem que

6 Não é foco neste trabalho nos debruçarmos mais detalhadamente acerca deste movimento. Para isso, ver literatura indicada. 
busca problematizar a produção de alimentos, correlacionando isso com atividades agropecuárias, pesquisas em organismos geneticamente modificados, saúde humana e impactos ambientais. Por exemplo, os estudantes sugeriram que "- É do interesse de um fazendeiro manter as vacas saudáveis (por exemplo, fazendas futuras podem ter "câmeras de vídeo na fazenda que emitem um sinal sonoro quando algo está errado")." (p. 698, tradução nossa); e ainda: “- Mudanças futuras que possam tornar a pecuária leiteira mais lucrativa tenderão a se concentrar na melhoria da produção de leite de vaca e nas tecnologias envolvidas na coleta e no tratamento eficiente do leite (por exemplo, "robôs ordenhando vacas e examinando vacas doentes")." (p. 698, tradução nossa). O destaque quanto ao movimento Future Studies reside no fato de que ele almeja desenvolver nos alunos a capacidade de inventar, detectar, analisar e desenvolver possíveis perspectivas futuras para situações-problemas atuais (ver Amara, 1981; Bell, 1996; Lloyd, \& Wallace, 2004; Pedretti, \& Nazir, 2011); o que se alinha com a possibilidade de atividades ligadas à resolução de problemas tais quais se propõe no ensino baseado em QSC.

\section{Eixo 5 - Compreensão e mobilização de conteúdo}

Neste eixo, vemos a predominância do nível 3 (15 trabalhos), o que representa que, nestas propostas, além da dimensão conceitual e procedimental, houve também a mobilização da dimensão atitudinal dos conteúdos abordados. Ou seja, um ensino para além dos conceitos, fatos, procedimentos e técnicas, mas, sim, que se preocupa com o ensino de valores e atitudes. Como na proposta realizada no artigo 17, que teve como QSC norteadora o tema poluição das águas. Neste trabalho, os autores abordaram, além dos conceitos e fatos (poluição ambiental, a história do Parque São Bartolomeu, poluição hídrica, entre outros), e procedimentos e métodos (identificação de contaminantes; seleção, descrição e comparação de materiais, informações e fenômenos, etc.), também valores e atitudes como "reflexão sobre as relações entre formas de usos antrópicos da natureza e consequências socioambientais" (p. 1057), "compreensão do valor da água" (p. 1057) e "discussão de valores e consideração moral da natureza" (p. 1058). No artigo 2, "os alunos praticaram o ativismo sócio-científico fora da sala de aula: organizando um teatro de marionetes para toda a comunidade para chamar a atenção para o tratamento da água" (p. 10, tradução nossa). Ainda, no artigo 5, em que se explorou o tema de trabalho infantil, "O elemento comum de ser criança e as suposições sobre o que as crianças deveriam fazer parecem ter causado respostas emocionais poderosas, dando ao ativista emergente o senso de urgência necessário para criar ou fazer mudanças benéficas nos sistemas sociais" (p. 1164, tradução nossa). O artigo 6 indica que os estudantes desenvolveram, além da compreensão de conhecimentos científicos relacionados à temática da QSC, algumas habilidades para busca de informações com o uso de tecnologias e no livro didático de biologia, e para a discussão sobre hábitos alimentares saudáveis e não saudáveis, considerando também suas próprias experiências pessoais.

No artigo 11, apesar de haver apontamento, pelos estudantes, de questões atitudinais (política, moral, comportamento moral: "apropriação indevida de dinheiro 
público. Acesso VIP ao estádio... A prática do racismo entre as pessoas” [p. 6]), não há problematização nem discussão desses aspectos. Nesse sentido, foram trabalhadas as dimensões conceituais e procedimentais, uma vez que os estudantes, "Em pequenos grupos, levantavam o que consideravam evidências científicas, ambientais, sociais e econômicas a partir de múltiplas fontes" (p. 4). A discussão da aplicação da proposta no artigo 8 não explicita valores relacionados à temática; apesar do trabalho em equipe, não se discute os valores dessa atividade. Nesse caso, percebemos a dimensão procedimental: "Pode-se obter informações sobre preparações vitamínicas consultando um médico, farmacêutico, pais ou lendo na internet ou no folheto informativo" (p. 170, tradução nossa); e conceitual: "os alunos tendiam a ser mais explícitos, escreveram que 'uma vitamina é um suplemento nutricional' ou escreveram uma função específica de uma vitamina como um 'nutriente protetor"' (p. 169, tradução nossa). Já no artigo 18, em que não há muitos detalhamentos sobre a proposta de ensino, pois o artigo não tem o objetivo de discutir a intervenção, apesar de haver discussão com os estudantes sobre a temática, com diferentes posicionamentos, não foram explicitadas dimensões procedimentais e atitudinais dos conteúdos trabalhados.

A mobilização da dimensão atitudinal dos conteúdos é de fundamental importância em um ensino baseado em QSC, visto que a avaliação e o julgamento moral estão ligados à tomada de decisão, sendo que, por vezes, é recorrendo a padrões morais, por exemplo, que estudantes fazem suas escolhas (Sadler, \& Zeidler, 2004). Ademais, com a articulação entre as três dimensões dos conteúdos - conceitual, procedimental e atitudinal - associada a uma abordagem mais progressista de ensino (como em algumas vertentes da Educação CTSA), por meio de estratégias ativas de ensino (por exemplo, o ensino baseado em QSC), poderemos atuar formando cidadãos capazes de realizar ações sociopolíticas nos meios em que transitam (Conrado, \& Nunes-Neto, 2015; Pedretti, \& Nazir, 2011).

Deste modo, podemos também perceber como os eixos elencados apresentamse de modo integrado nos contextos reais de aplicação, já que, a partir do momento em que os estudantes compreendem as dimensões conceituais, procedimentais e atitudinais dos conteúdos ligados à educação científica, eles podem perceber a relevância daqueles assuntos para entenderem como as esferas da ciência, tecnologia, sociedade e ambiente estão relacionadas e ligadas diretamente ao seu convívio diário; assim, poderão analisar os possíveis pontos de vista, percebendo os jogos de interesse por detrás das controvérsias socioambientais que apresentam-se a eles diariamente e tomando suas decisões de modo socioambientalmente responsável, além de estarem, também, preparados para, enquanto cidadãos, planejarem e realizarem ações de caráter sociopolítico, buscando colaborar para a construção de uma sociedade socioambientalmente mais justa (Conrado, \& Nunes-Neto, 2018b; Hodson, 2018; Bencze et al., 2018; Conrado, 2017; Silva, \& El-Hani, 2014). 


\section{Combinação dos Eixos e caracterização geral das propostas de ensino baseadas em QSC}

Ao compararmos o somatório da pontuação de cada eixo para todos os trabalhos, percebemos que o eixo 5 foi o mais desenvolvido em todos os trabalhos (56 pontos, $88,9 \%$, considerando a possibilidade de somar 63 pontos), seguido do eixo 1 (47 pontos, $74,6 \%$ ) e o eixo 2 (40 pontos). Os eixos 3 (34 pontos, 63,5\%) e 4 (31 pontos, 49,2\%) foram os menos desenvolvidos, considerando a avaliação geral dos trabalhos.

Por um lado, isso pode significar relações estreitas entre a aplicação da perspectiva CTSA e a explicitação de dimensões CPA dos conteúdos (Conrado, 2017), já que as propostas avaliadas que tratam das relações CTSA da QSC, envolvendo o cotidiano dos estudantes, facilitam a explicitação de diferentes dimensões do conteúdo, permitindo abordar não apenas conceitos e procedimentos relacionados à ciência e à tecnologia, mas também discutir valores e normas sociais, e planejar e implementar transformações sociais, coletivas e/ou individuais (Conrado, \& Nunes-Neto, 2018b). Por outro lado, os eixos 3 e 4 também estão bem relacionados, e, muitas vezes não são fáceis de se desenvolver em apenas uma única intervenção, sobretudo com estudantes que não estão acostumados com processos de argumentação, posicionamento, tomada de decisão e organização de ações sociopolíticas. Assim, é pouco provável conseguir desenvolver boa argumentação para justificar adequadamente as decisões, além de limitações que podemos ter, por conta da idade dos estudantes e os hábitos destes com aulas expositivas, para discutir propostas e ações para a solução de problemas (Dias, \& Silva, 2010). Contudo, mesmo com essas e outras limitações, percebemos que, em nossa análise desses eixos, para alguns artigos (ex. 2, 3, 5), ainda foi possível que o estudante refletisse sobre diferentes posicionamentos, percebesse o conteúdo científico que pode embasar possíveis caminhos, adotasse um posicionamento, e participasse do planejamento e da execução de ações sociopolíticas voltadas à solução da QSC estudada (Bencze et al., 2018; Reis, 2013).

De um modo geral, considerando a possibilidade de somar até 15 pontos nos cinco eixos, grande parte das propostas analisadas (47,62\%, 10 trabalhos) alcançou de 12 a 14 pontos, representando uma elevada sofisticação nas características avaliadas. Ainda, 6 trabalhos $(28,57 \%)$ totalizaram de 8 a 10 pontos, sugerindo uma representatividade média de abrangência das características analisadas nos cinco eixos. Por fim, 5 trabalhos $(23,81 \%)$ indicaram pontuação entre 5 e 6 , sendo classificados, neste artigo, como aqueles que menos apresentaram, na descrição da proposta de ensino e sua aplicação, características do ensino baseado em QSC. Aplicando a pontuação no gráfico de radar, podemos observar que as propostas $1,2,3,4,6,7,10,14,15,17$ obtiveram pontuações totais entre 12 e 14 pontos para os 5 eixos (Figura 4); os trabalhos 5, 11, 13,16, 20 e 21 obtiveram entre 8 e 10 pontos no somatório dos 5 eixos (Figura 5); enquanto que os trabalhos $8,9,12,18,19$ obtiveram entre 5 e 6 pontos (Figura 6 ). 


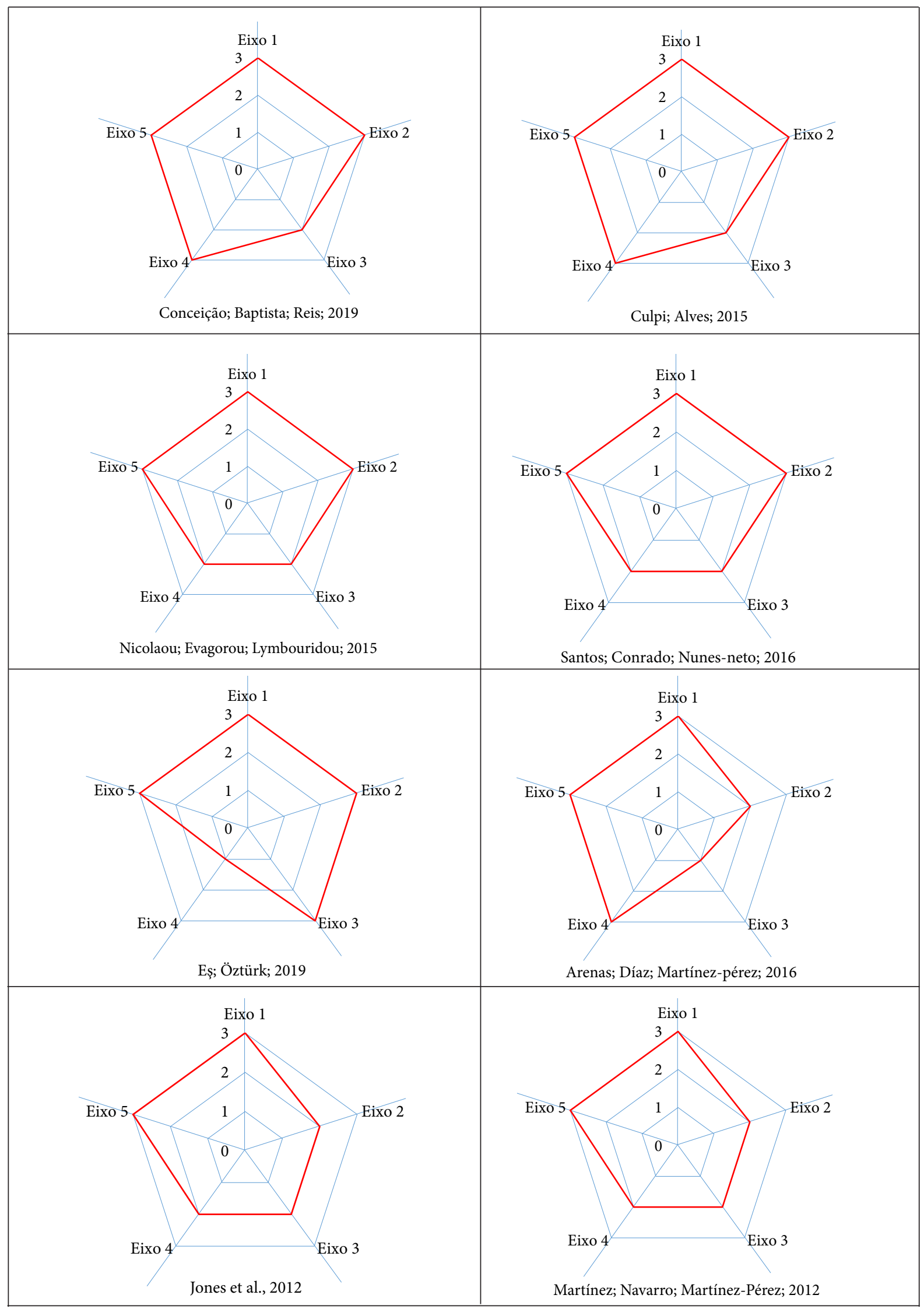

Figura 4. Propostas que alcançaram maiores pontuações nos 5 eixos (continua) 


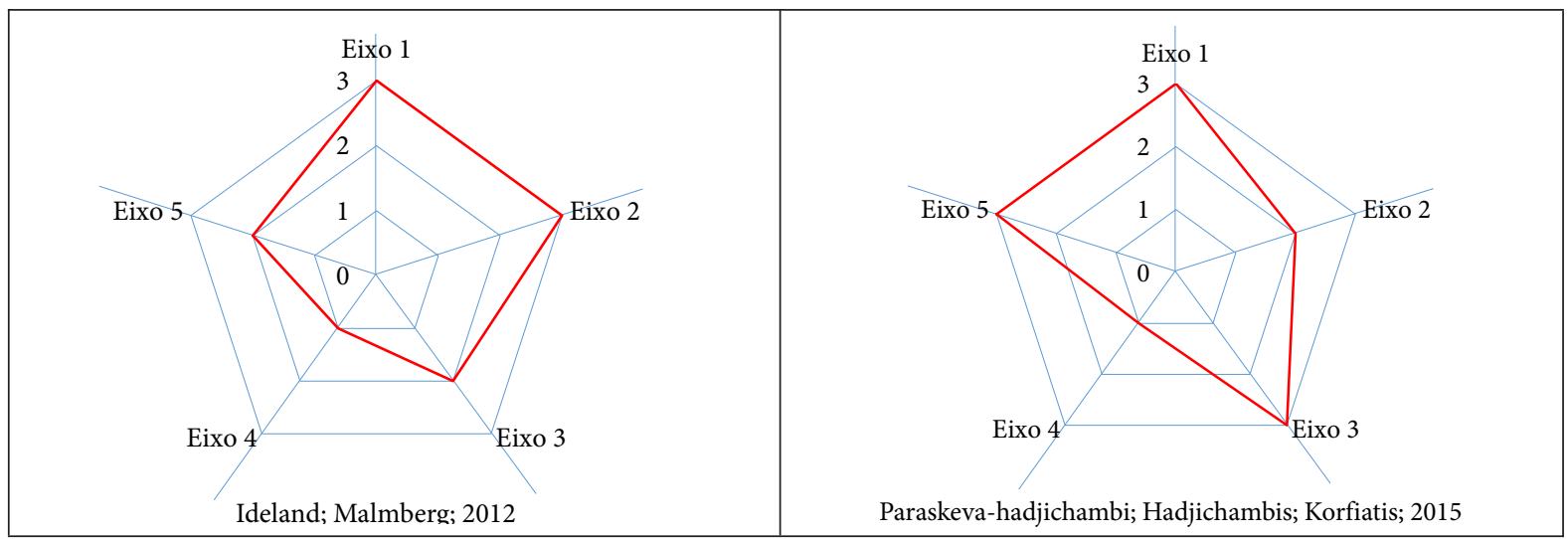

Figura 4. Propostas que alcançaram maiores pontuações nos 5 eixos (continuação)

Particularmente, os artigos 2 e 3 tratam de QSC associadas à água (contaminação e consumo, respectivamente) e apresentaram o mesmo padrão no gráfico; ainda, o artigo 2 , apesar de se tratar de um tema socioambientalmente relevante, não foi explicitado no texto uma discussão da problemática ambiental em si, predominando reflexões sobre interações humanas na natureza que afetam os humanos. $\mathrm{O}$ artigo 3, apesar de explicitar uma discussão mais aprofundada sobre as relações CTSA envolvidas na QSC, ainda assim mostra uma ênfase na espécie humana. Nesse sentido, para ambos os trabalhos, a dimensão ambiental parece ter representado apenas um valor instrumental, numa perspectiva antropocêntrica (Santos, Conrado, \& Nunes-Neto, 2018). Quanto à realização de ações sociopolíticas, no artigo 2 são indicadas várias atividades (mais coletivas: criação de um clube de rádio na escola e um teatro de fantoches para a comunidade), assim como no artigo 3 (mais individuais: ter consciência sobre o uso individual), mostrando a importância da realização de ações, após a discussão e o posicionamento sobre a QSC pelos estudantes. Por fim, quanto ao processo argumentativo para tomada de decisões informadas, em ambos os artigos, não percebemos detalhamentos sobre os fundamentos das posições assumidas pelos estudantes, ou seja, pela descrição das propostas e aplicações nos textos, faltou aos estudantes assumir uma decisão sobre o posicionamento, pois apenas explicitaram a opinião sobre a controvérsia, sem estabelecerem a necessidade de ações justificadas por conteúdos mobilizados nos processos envolvidos na intervenção (Dionor, et al., 2019; Hodson, 2018).

Ainda, os artigos 14 e 17 apresentaram contextualização das QSC no cotidiano dos estudantes, facilitando o engajamento destes para a discussão e a busca de soluções. Além disso, ambos os artigos conseguiram mobilizar conteúdos científicos (conceitos e princípios relacionados com o tema estudado e procedimentos de coleta e análise de dados), bem como mobilizar dimensões atitudinais dos conteúdos (discutindo questões comportamentais, no artigo 14 e questões éticas da QSC, no artigo 17), além do desenvolvimento de possíveis soluções para as QSC e posicionamento, considerando os dados levantados.

Dessa maneira, a partir dessa análise preliminar, acreditamos que, de um modo geral, os artigos que apresentaram os 5 eixos, em níveis mais abrangentes de sofisticação, 
conseguiram desenvolver e aplicar uma proposta de ensino baseado em QSC com boa qualidade, considerando as características avaliadas, facilitando, assim, atingir melhores resultados educacionais com os estudantes.

Eixo 5 Eixo 2

Figura 5. Propostas que alcançaram entre 8 e 10 pontos nos 5 eixos

Adicionalmente, de acordo com nossa análise, levando em conta o relatado nos artigos analisados, há propostas de ensino que consideramos possuir limitações, com relação ao alcance dos níveis de abrangência nos eixos; isto é, que, apesar de possuírem 
determinadas características que favorecem um ou mais eixos, não favorecem outros. Por ex. nos artigos 13 e 20 (e também em 2, 3, 4, 6, 13, 14, 17), os eixos 2 e 5 aparecem com mais expressividade. Isso pode ocorrer uma vez que a motivação (gerada pelo tema estar presente no cotidiano do estudante) e a aplicação do conteúdo são coerentes com uma perspectiva mais ampla de conteúdo, incorporando as dimensões procedimental e atitudinal (Autor, 2018). Um vínculo possível estaria na situação em que o estudante, se sentindo motivado pela temática, necessariamente mobiliza dimensões do conteúdo para além da dimensão conceitual, refletindo e aplicando o conteúdo científico para aprofundar seu entendimento e sua atuação sobre a QSC. Contudo, se, apesar de um forte desenvolvimento da proposta nos eixos 2 e 5, houver pouca ênfase no eixo 3 (por exemplo, o que encontramos nos artigos 1, 13 e 20), o estudante poderia ter dificuldades para desenvolver habilidades de comunicação e posicionar-se sobre a temática, ou, ainda, para tomar decisões informadas, relacionadas à QSC estudada (Mendonça, \& Justi, 2013). Ainda, nesse mesmo contexto, se, mesmo com boa expressividade nos eixos 2 e 5, houver pouca ênfase no eixo 4 (por exemplo, o que encontramos nos artigos 4, 6, 13 e 20), o estudante poderia ter dificuldades para entender a controvérsia, buscar e propor soluções, e, por fim, planejar-se e agir em relação às suas decisões e ponderações. Nesse sentido, concordamos com Sadler, Foulk, \& Friedrichsen (2017), quando indicam a necessidade de maiores aprofundamentos teóricos e empíricos no contexto de pesquisas e aplicações envolvendo o ensino baseado em QSC. Além disso, percebemos que, quanto mais abrangente for o desenvolvimento das propostas nesses cinco eixos, melhor poderá ser o resultado para o alcance de objetivos educacionais, no ensino de ciências.

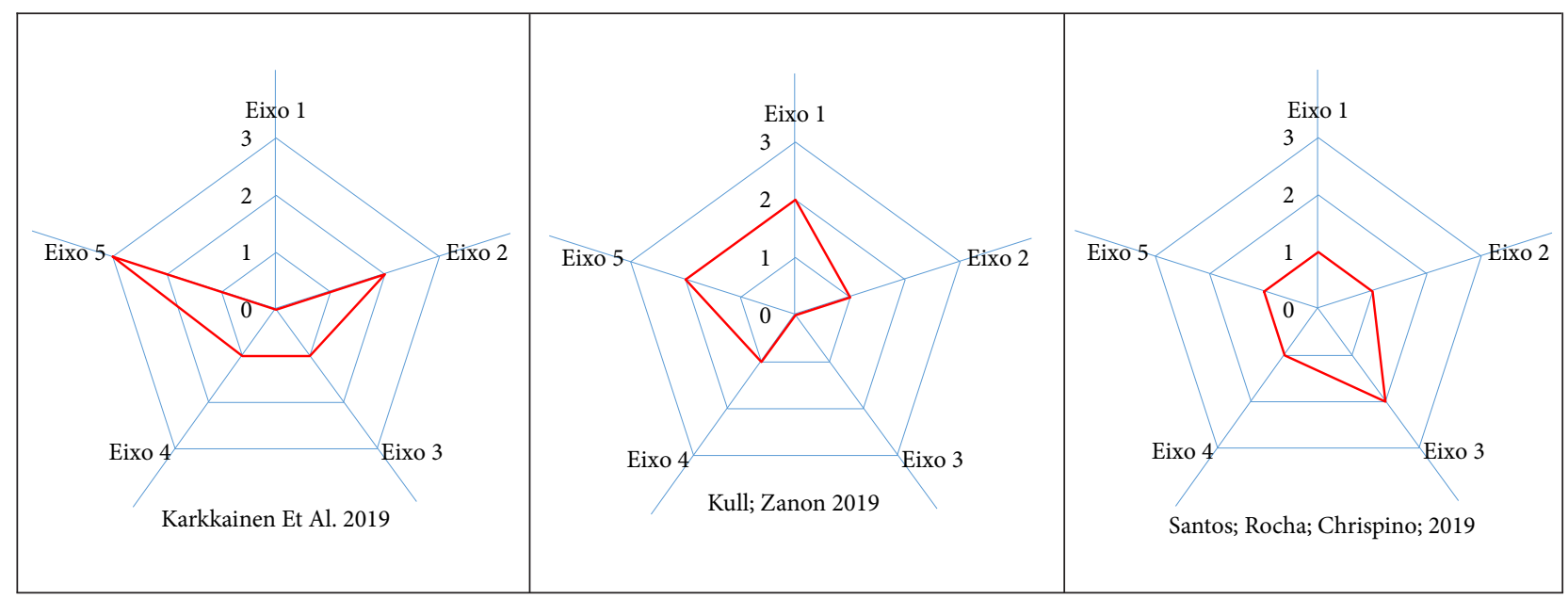

Figura 6. Propostas que alcançaram menores pontuações nos 5 eixos (continua) 


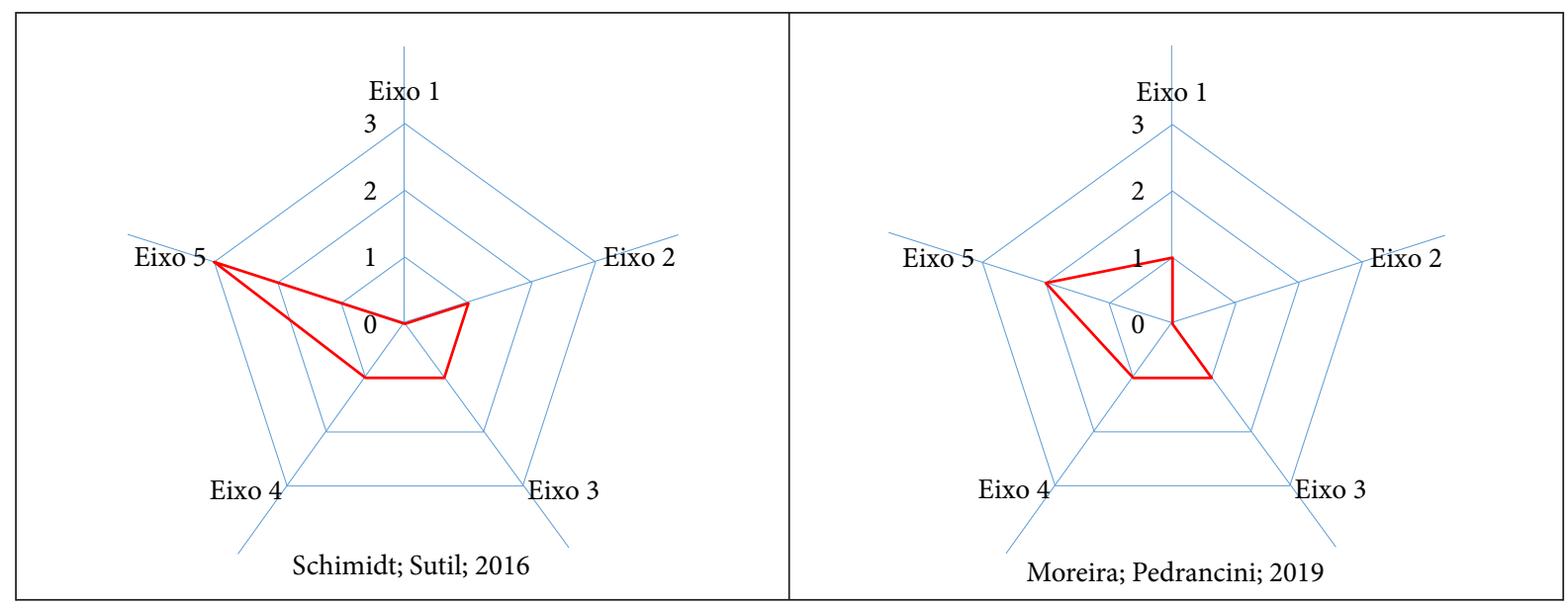

Figura 6. Propostas que alcançaram menores pontuações nos 5 eixos (continuação)

No artigo 8, apesar dos estudantes mobilizarem vários conteúdos sobre vitaminas, não se priorizou uma discussão de relações CTS presentes na temática; apesar de se discutirem diferentes pontos de vista dos estudantes, estes não precisaram, necessariamente, apresentar um posicionamento informado; apesar de discutirem algumas controvérsias presentes na QSC, não foram relatadas soluções e decisões estabelecidas pelos estudantes. Por fim, não percebemos, considerando o que foi relatado no artigo analisado, uma discussão em sala sobre valores relacionados à temática e nem em relação aos comportamentos dos estudantes durante as atividades da intervenção. Portanto, a proposta apresentada no artigo, em relação à nossa análise, demandaria alguns ajustes para atingir determinados objetivos educacionais, como um letramento científico crítico ou, no mínimo, a capacidade para entender relações CTSA da QSC.

No artigo 19, que objetivou discutir questões relacionadas à biotecnologia, percebemos que o desenvolvimento de atividades utilizando um programa de jogo demandou grande quantidade de tempo, prejudicando uma das etapas da intervenção, que seria o desenvolvimento de ações sociopolíticas na escola. Além disso, considerando as informações fornecidas no artigo, provavelmente os estudantes não conseguiram associar os temas de seus grupos (Energia; Lixo; Poluição; Saúde; e Água), com a temática principal (biotecnologia) e as relações CTSA da QSC. Adicionalmente, o conteúdo científico pareceu mobilizado de forma superficial, tendo maior ênfase o desenvolvimento de atividades relacionadas ao ambiente do jogo. Todavia, o artigo discute dimensões atitudinais dos conteúdos desenvolvidas pelos estudantes no processo de intervenção. De modo geral, considerando as informações fornecidas pelo trabalho analisado, salientamos que um planejamento mais detalhado, considerando o contexto espacial e temporal, as características dos estudantes, e as demandas do currículo pode favorecer a obtenção de maior êxito no alcance de objetivos educacionais (MartínezPérez, \& Carvalho, 2012; Santos, \& Kato, 2013).

Em grande parte $(61,90 \%$ no Nível 3 do Eixo 1) das propostas (13), percebemos a preocupação em pensar e executar um ensino que prepare os estudantes para 
compreender como ocorre a interação entre as esferas da ciência e da tecnologia e as esferas sociais e ambientais, indicando a QSC de modo contextualizado ao cotidiano destes estudantes. Percebemos, nas propostas analisadas (38,09\% no Nível 3 do Eixo 2), a articulação dos conteúdos da educação científica de modo que os estudantes percebam como esses temas estão presentes em seu cotidiano, para que assim possam reconhecer a importância do conteúdo científico escolar. Ademais, em 11 (52,38\% no Nível 2 do Eixo 3 ) das propostas analisadas, há a proposição de um planejamento didático que prepare os estudantes para debaterem pontos de vistas com argumentos, mas sem a própria tomada de decisão consciente e justificada por argumentos qualificados, visando uma transformação, seja coletiva seja individual.

Assim, as propostas precisam investir em momentos que busquem, através de uma análise crítica, que estudantes proponham possíveis soluções para os problemas discutidos, estimulando-os para engajamento, planejamento e execução de ações de caráter sociopolítico em nível individual e/ou coletivo, visto que 11 (52,38\% no Nível 1 do Eixo 4) intervenções não abarcam essa preparação/formação, sobretudo se o objetivo educacional da proposta é contribuir para a formação de cidadãos socioambientalmente responsáveis. Entretanto, em 15 (71,42\% no Nível 3 do Eixo 5) propostas, percebemos que houve a mobilização de conteúdos nas dimensões conceitual, procedimental e atitudinal, condição necessária para compreender com maior profundidade as QSC no contexto educacional.

Por fim, em relação à apresentação dos dados, uma possível limitação que percebemos, quanto ao uso de gráfico de radar, está no fato de que este tipo de representação pode não ser uma opção adequada, quando há poucas informações para avaliar (neste caso, apenas 5 eixos) e quando os dados (nesse caso, os níveis) são discretos (ao invés de contínuos, o que possibilitaria maior precisão na classificação das propostas).

Nesse contexto, vale destacar que cada eixo representa uma combinação de ao menos duas características básicas do ensino baseado em QSC, segundo a literatura (Ratcliffe, \& Grace, 2003). Ao realizarmos essa análise, percebemos que talvez o desmembramento dessas características agrupadas poderia facilitar e pormenorizar a caracterização das propostas de ensino, em uma análise posterior. Assim, separar as características dos 5 eixos para estabelecer 10 eixos (por exemplo: Relações CTSA da QSC; Contextualização da QSC com o cotidiano; Motivação a partir da realidade do estudante; Aplicação de conteúdos científicos; Argumentação; Posicionamento; Análise de controvérsia; Resolução de problemas; Compreensão conceitual; Mobilização de dimensões CPA dos conteúdos), bem como ampliar a granulosidade da ferramenta (em mais níveis de abrangência), permitiria captar maiores detalhes sobre os dados analisados. 


\section{Conclusões e Implicações}

Podemos perceber, através da metodologia empregada e dos resultados obtidos, que as propostas didáticas presentes na literatura apresentam, de modo geral, as características apontadas na literatura - relevância e contextualização, motivação e aplicação, argumentação e posicionamento, análise e resolução de problemas, e compreensão e mobilização de conteúdo - que as qualificam como estruturadas no que diz respeito ao ensino baseado em QSC. É possível que as características elencadas, nesta ferramenta, venham a constituir uma matriz de referência, para futuras explorações da literatura focada sobre as QSC ou temas relacionados, o que dependerá de novas avaliações (como, por exemplo, envolvendo o ensino médio e técnico) e refinamentos (como a elaboração de mais eixos e níveis de abrangência) a partir da análise aqui empreendida.

Em relação à pergunta desta pesquisa, percebemos que há uma grande variação dos resultados, em relação ao alcance das características nos cinco eixos, considerando os trabalhos analisados. Isso pode significar que muitas das propostas possuem limitações relevantes, o que coloca, do nosso ponto de vista, um desafio para a área: aumentar o rigor teórico e empírico das propostas de ensino baseadas em QSC. Por outro lado, é possível que as propostas tenham sido, de fato, bem desenvolvidas, nas características essenciais do ensino baseado em QSC, mas tal desenvolvimento não tenha se refletido no texto, pois, muitas vezes, o artigo analisado não visou exatamente a discussão da proposta e sua aplicação, mas teve outros objetivos, como, por exemplo, avaliar a formação de professores, a concepção de estudantes, etc. Ou, ainda, apresentou e discutiu apenas parte da aplicação da proposta, reduzindo as informações possíveis sobre a proposta, por conta do que foi efetivamente relatado no artigo. Adicionalmente, a partir da análise das características presentes nos trabalhos avaliados, apresentamos uma hipótese: em uma proposta de ensino baseada em QSC, quanto maior a abrangência dos níveis de sofisticação e quanto mais presentes os cinco eixos, então, melhor será o resultado para o alcance de objetivos educacionais.

Portanto, cabe ressaltar que o presente trabalho constitui uma análise inicial da literatura; e, por ser um estudo preliminar, com potencial para ser ampliado, um aprofundamento sobre o instrumento de análise poderia alterar a organização e o ponto de vista sobre os dados aqui discutidos. Desse modo, para uma conclusão mais precisa sobre a literatura, inclusive atualizada e ampliada para abarcar outras bases de dados acadêmicos e outros níveis de ensino, apontamos a necessidade de maior investigação sobre as relações entre esses diferentes eixos e o impacto deles no alcance de objetivos da educação científica das propostas de ensino baseadas em QSC. Inclusive, a ferramenta analítica elaborada pode ser aplicada em outros contextos de utilização de QSC como norteadoras da prática educativa, como, por exemplo, em etapas de planejamento de futuras propostas ou como um meio de avaliação de protótipos.

Por fim, destacamos que o próprio processo de análise dos artigos serviu como base para reflexões sobre o aperfeiçoamento da ferramenta analítica, para cada vez 
melhor descrever e compreender características do ensino baseado em QSC nas práticas pedagógicas. Tais perspectivas poderão ser adotadas em trabalhos futuros, inclusive com ampliações e atualizações do corpus de análise.

\section{Agradecimentos}

O presente trabalho foi realizado com apoio da Coordenação de Aperfeiçoamento de Pessoal de Nível Superior - Brasil (CAPES) - Código de Financiamento 001. Os autores agradecem também ao INCT-INTREE - CNPQ/CAPES/FAPESB.

\section{Referências}

Aikenhead, G. S. (2009). Research into STS science education. Revista Brasileira de Pesquisa em Educação em Ciências, 9(1), 1-21.

Amara, R. (1981). The futures field: Searching for definitions and boundaries. Futures, $15(2), 25-29$.

Auler, D., \& Bazzo, W. A. (2001). Reflexões para a implementação do Movimento CTS no contexto educacional brasileiro. Ciência \& Educação, 7(1), 1-13. http://dx.doi. org/10.1590/S1516-73132001000100001

Bell, W. (1996). An overview of futures studies. In R. Slaughter (Org.), The knowledge base of futures studies: Foundations (pp. 28-56). DDM Media.

Bencze, L., Carter, L., \& Krstovic, M. (2014). Science \& Technology Education for Personal, Social \& Environmental Wellbeing: Challenging Capitalists' Consumerist Strategies. Revista Brasileira de Pesquisa em Educação em Ciências. 14(2), 39-56.

Bencze, L., Halwany, S. E., Krstovic, M., Milanovic, M., Phillips, C., \& Zouda, M. (2018). Estudantes agindo para abordar danos pessoais, sociais e ambientais relacionado à ciência e à tecnologia. In D. M., Conrado, \& N. F., Nunes-Neto (Orgs.), Questões Sociocientíficas: Fundamentos, propostas de ensino e perspectivas para ações sociopolíticas (pp. 515-560). EDUFBA.

Canzonieiri, A. M. (2010). Metodologia da pesquisa qualitativa na saúde. Vozes.

Cavalcanti, D. B., Costa, M. A. F., da, \& Chrispino, A. (2014). Educação Ambiental e Movimento CTS, caminhos para a contextualização do Ensino de Biologia. Revista Práxis, (12), 27-42. https://doi.org/10.25119/praxis-6-12-646

Coll, C., Pozo, J. I., Sarabia, B., \& Valls, E. (1992). Los contenidos en la reforma: Enseñanza $y$ aprendizaje de conceptos, procedimientos y actitudes. Santillana S.A.

Conrado, D. M. (2017). Questões Sociocientíficas na Educação CTSA: Contribuições de um modelo teórico para o letramento científico crítico. (Tese de Doutorado em Ensino, Filosofia e História das Ciências). Universidade Federal da Bahia, Salvador. 
Conrado, D. M., \& Nunes-Neto, N. F. (2018a). Questões Sociocientíficas: Fundamentos, propostas de ensino e perspectivas para ações sociopolíticas. EDUFBA.

Conrado, D. M., \& Nunes-Neto, N. F. (2018b). Questões sociocientíficas para a aprendizagem de conteúdos conceituais, procedimentais e atitudinais no Ensino de Ciências. In D. M. Conrado, \& N. F., Nunes-Neto (Orgs.), Questões Sociocientíficas: Fundamentos, propostas de ensino e perspectivas para ações sociopoliticas (pp. 77-118). EDUFBA.

Costa, E. A. da. (2005). Gestão estratégica (4. ed.) Saraiva.

Cunha, R. B. (2017). Alfabetização científica ou Letramento científico? interesses envolvidos nas interpretações da noção de scientific literacy. Revista Brasileira de Educação, 22(68), 169-186. http://dx.doi.org/10.1590/s1413-24782017226809

Dias, A. S., \& Silva, A. P. B., da (2019). A argumentação em aulas de ciências como uma alternativa ao uso das novas tecnologias da informação e comunicação em cenários comuns à escola pública brasileira. Revista Brasileira de Estudos Pedagógicos, 91(229), 622-633. http://dx.doi.org/10.24109/2176-6681.rbep.91i229.633

Dionor, G. A. (2018). Propostas de ensino baseado em questões sociocientíficas: Uma análise sistemática da literatura acerca do ensino de ciências na educação básica. (Dissertação de Mestrado em Ensino, Filosofia e História das Ciências). Universidade Federal da Bahia, Salvador.

Dionor, G. A., Conrado, D. M., Martins, L., \& Nunes-Neto, N. F. (2020). Análise de propostas de ensino baseadas em QSC: Uma revisão da literatura na educação básica. Alexandria: Revista de Educação em Ciência e Tecnologia, 13(1), 197-224. http://dx.doi. org/10.50007/1982-5153.2020v13n1p197

Dionor, G. A., Martins, L. Conrado, D. M., \& Nunes-Neto, N. F. (2019). Caracterizando propostas de ensino baseado em Questões Sociocientíficas. In Atas do XII Encontro Nacional de Pesquisa em Educação em Ciências. ABRAPEC.

Drees, C. (2007). Um modelo de indicadores alinhado aos objetivos estratégicos da unidade de negócios associado a uma ferramenta de gestão: Caso da unidade Óleos Vegetais do Grupo Maeda S. A. Agroindustrial. (Dissertação de Mestrado em Agronegócio). Universidade Federal de Goiás, Goiânia.

Gil, A. C. (2017). Como elaborar projetos de pesquisa (4. ed.). Atlas.

Hand, B. M., Alvermann, D. E., Gee, J., Guzzetti, B. J., Norris, S. P., Phillips, L. M., \& Yore, L. D. (2003). Message from the "Island Group": What is scientific literacy? Journal of Research in Science Teaching, 40, 607-615. https://doi.org/10.1002/tea.10101

Hodson, D. (1994). Seeking directions for change: The personalisation and politicisation of science education. Curriculum Studies, 2(1), 71-98. https://doi. org/10.1080/0965975940020104 
Hodson,D.(2003). Timeforaction:Scienceeducation foranalternativefuture.International Journal of Science Education, 25, 645-670. https://doi.org/10.1080/09500690305021

Hodson, D. (2004). Going beyond STS: towards a curriculum for sociopolitical action. The Science Education Review, 3(1), 2-7.

Hodson, D. (2010). Science education as a call to action. Canadian Journal of Science, Mathematics and Technology Education, 10(3), 197-206. https://doi.org/10.1080/14926 156.2010.504478

Hodson, D. (2011). Looking to the future: Building a curriculum for social activism. Sense Publishers. https://www.sensepublishers.com/media/621-looking-to-the-future.pdf

Hodson, D. (2018). Realçando o papel da ética e da política na educação científica: algumas considerações teóricas e práticas sobre questões sociocientíficas. In D. M., Conrado, \& N. F., Nunes-Neto (Orgs.), Questões Sociocientíficas: Fundamentos, propostas de ensino e perspectivas para ações sociopolíticas (pp. 27-58). EDUFBA.

Jiménez-Aleixandre, M. P., \& Frederico-Agraso, M. (2006). A argumentação sobre questões sociocientíficas: Processos de construção e justificação do conhecimento em sala de aula. Educação em Revista, 43, 13-33.

Jiménez-Aleixandre, M. P., \& Pereiro-Munhoz, C. (2002). Knowledge producers or knowledge consumers? Argumentation and decision making about environmental management. International Journal of Science Education, 24(10), 1171-1190. https://doi. org/10.1080/09500690210134857

Jiménez-Aleixandre, M. P., Rodríguez A. B., \& Duschl, R. A. (2000). “Doing the Lesson” or "Doing Science": Argument in High School Genetics. Science Education, 84, 757-792. https://doi.org/10.1002/1098-237X(200011)84:6<757::AID-SCE5>3.0.CO;2-F

Kolstø, S. D. (2001). To trust or not to trust - "pupils" ways of judging information encountered in a socioscientific issue. International Journal of Science Education, 23(9), 877-901. https://doi.org/10.1080/09500690010016102

Lewis, J., \& Leach, J. (2006). Discussion of Socio-scientific Issues: The role of science knowledge. International Journal of Science Education, 28(11), 1267-1287. https://doi. org/10.1080/09500690500439348

Lloyd, D., \& Wallace, J. (2004). Imaging the future of science education: the case for making futures studies explicit in student learning. Studies in Science Education, 40(1), 139-177. https://doi.org/10.1080/03057260408560205

Martínez-Pérez, L. F. (2012). Questões sociocientíficas na prática docente: Ideologia, autonomia e formação de professores. Editora UNESP. http://aia-cts.web.ua.pt/wpcontent/uploads/2015/08/1-Questoes_sociocientificas_na_pratica_docente-Web_2.pdf 
Martínez-Pérez, L. F., \& Carvalho, W. L. P. de. (2012). Contribuições e dificuldades da abordagem de questões sociocientíficas na prática de professores de ciências. Educação e Pesquisa, 38(3), 727-741. https://doi.org/10.1590/S1517-97022012005000014

Martínez-Pérez, L. F., \& Parga Lozano, D. L. (2013). La emergencia de las cuestiones sociocientíficas en el enfoque CTSA. Góndola, 8(1), 23-35. https://doi. org $/ 10.14483 / 23464712.5021$

Martínez-Pérez, L. F., Carvalho, W. L. P. de, Lopes, N. C., Carnio, M. P., \& Vargas, N. J. B. (2011). Abordagem de questões sociocientíficas no Ensino de Ciências: Contribuições à pesquisa da área. In Atas do VIII Encontro Nacional de Pesquisa em Educação em Ciências. ABRAPEC.

Mendes, M. R. M. (2012). A argumentação em discussões sociocientíficas: o contexto e o discurso. (Tese de Doutorado em Educação). Universidade de Brasília, Brasília.

Mendes, M. R. M., \& Santos, W. L.P. (2013). Argumentação em discussões sociocientíficas. Investigações em Ensino de Ciências, 18(3), 621-643.

Mendonça, P. C. C., \& Justi, R. S. (2013). Ensino-Aprendizagem de Ciências e Argumentação: Discussões e Questões Atuais. Revista Brasileira de Pesquisa em Educação em Ciências. 13(1), 187-216.

Mundim, J. V., \& Santos, W. L. P. dos. (2012). Ensino de ciências no ensino fundamental por meio de temas sociocientíficos: análise de uma prática pedagógica com vista à superação do ensino disciplinar. Ciência \& Educação, 18(4), 787-802.

Newton, P., Driver, R., \& Osborne, J. (1999). The place of argumentation in the pedagogy of school science. International Journal of Science Education, 21(5), 553-576. https://doi. org/10.1080/095006999290570

Ornstein, R. (1989). Gráfico Radar: uma forma alternativa de medir o desempenho econômico-financeiro. Revista do CRCRS, 18(56), 2-8.

Oulton, C., Dillon, J., \& Grace, M. (2004). Reconceptualising the teaching of controversial issues. International Journal of Science Education, 26(4), 411-423. https:// doi.org/10.1080/0950069032000072746

Pedretti, E. (2003). Teaching science, technology, society and environment (STSE) education: preservice teachers' philosophical and pedagogical landscapes. In D. Zeidler (Org.), The role of moral reasoning on socioscientific issues and discourse in science education (pp. 219-239). Kluwer Academic Publishers.

Pedretti, E., \& Nazir, J. (2011). Currents in STSE Education: Mapping a complex field, 40 years on. Science Education, 95(4), 601-626. https://doi.org/10.1002/sce.20435

Penha. S. P. (2012). Atividades sociocientíficas em sala de aula de física: As argumentações dos estudantes. (Tese de Doutorado em Ensino de Ciências). Universidade de São Paulo, São Paulo. 
Ratcliffe, M. (1997). Discussing socio-scientific issues in science lessons - pupils' actions and the teacher's role. School Science Review, 79(288), 55-59.

Ratcliffe, M., \& Grace, M. (2003). Science Education for Citizenship: Teaching socioscientific issues. Open University Press.

Reis, P. (2004). Controvérsias sócio-científicas: Discutir ou não discutir? Percursos de Aprendizagem na disciplina de Ciências da Terra e da Vida. (Tese de Doutorado em Educação). Faculdade de Ciências da Universidade de Lisboa, Lisboa.

Reis, P. (2013). Da discussão à ação sóciopolítica sobre controvérsias sócio-científicas: Uma questão de cidadania. Ensino de Ciências e Tecnologia em Revista, 3(1), 1-10.

Reis, P. (2014). Acción socio-política sobre cuestiones sociocientíficas: reconstruyendo la formación docente y el currículo. Uni-pluri/versidad, 14(2), 16-26.

Reis, P., \& Galvão, C. (2009). Teaching Controversial Socio-Scientific Issues in Biology and Geology Classes: A Case Study. Electronic Journal of Science Education, 13(1), 1-24.

Reske-Filho, A., \& Rocchi, C. A. de. (2008). Aplicação do Gráfico Radar na avaliação do desempenho das empresas de construção civil. In XV Congresso Brasileiro de Custos (p. $1)$.

Roberts, D. (2007). Scientific literacy/Science literacy. In S. Abell, \& N. Lederman (Orgs.), Handbook of research on science education (pp. 729-780). Lawrence Erlbaum.

Sadler, T. D. (2004). Informal Reasoning Regarding Socioscientific Issues: A Critical Review of Research. Journal of Research in Science Teaching, 41(5), 513-536. https://doi. org/10.1002/tea.20009

Sadler, T. D., \& Murakami, C. D. (2014). Socio-scientific Issues based teaching and learning: hydrofracturing as an illustrative context of a framework for implementation and research. Revista Brasileira de Pesquisa em Educação em Ciências, 14(2), 331-342.

Sadler, T. D., Foulk, J. A., \& Friedrichsen, P. J. (2017). Evolution of a model for socioscientific issue teaching and learning. International Journal of Education in Mathematics, Science and Technology, 5(2), 75-87.

Sadler, T. D., \& Donnelly, L. A. (2006). Socioscientific Argumentation: The effects of content knowledge and morality. International Journal of Science Education, 28(12), 1463-1488. https://doi.org/10.1080/09500690600708717

Sadler, T. D., \& Zeidler, D. L. (2005). Patterns of informal reasoning in the context of socioscientific decision-making. Journal of Research in Science Education, 42, 112-138. https://doi.org/10.1002/tea.20042

Sadler, T. D., \& Zeidler, D. L. (2009). Scientific Literacy, PISA, and Socioscientific Discourse: Assessment for Progressive Aims of Science Education. Journal of Research in Science Teaching, 46(8), 909-921. https://doi.org/10.1002/tea.20327 
Santos, J., Conrado, D. M., \& Nunes-Neto, N. (2018). Poluição hídrica: uma questão sociocientífica para abordar ética ambiental no ensino fundamental de ciências. In D. M. Conrado, \& N. F., Nunes-Neto (Orgs.), Questões Sociocientíficas: Fundamentos, propostas de ensino e perspectivas para ações sociopolíticas (pp. 191-212). EDUFBA.

Santos, P. G. F. dos, Lopes, N. C., Carnio, M. P., Carvalho, L. M. O. de, \& Carvalho, W. L. P. de. (2011). A abordagem de Questões Sociocientíficas no ensino de Ciências: uma compreensão das sequências didáticas propostas por pesquisas na área. In Atas do VIII Encontro Nacional de Pesquisa em Educação em Ciências. ABRAPEC.

Santos, W. L. P. dos, \& Kato, C. G. M. M. (2013). Limites e possibilidades do uso de situações problemas como recurso pedagógico: os temas controversos sócio científicos e as relações CTSA como perspectivas para o Ensino de Ciências. In Atas do IX Encontro Nacional de Pesquisa em Educação em Ciências. ABRAPEC.

Santos, W. L. P. dos, \& Schnetzler, R. P. (1997). Educação em Química: Compromisso com a cidadania. Ed. UNIJUÍ.

Santos, W. L. P. dos. (2007). Educação científica na perspectiva de letramento como prática social: Funções, princípios e desafios. Revista Brasileira de Educação, 12(36), 474-550. http://dx.doi.org/10.1590/S1413-24782007000300007

Santos, W. L. P. dos. (2008). Educação Científica Humanística em Uma Perspectiva Freireana: Resgatando a Função do Ensino de CTS. Alexandria, 1(1), 109-131.

Santos, W. L. P. dos, \& Mortimer, E. F. (2001). Tomada de decisão para ação social responsável no Ensino de Ciências. Ciência \& Educação, 7(1), 95-111. http://dx.doi. org/10.1590/S1516-73132001000100007

Santos, W. L. P. dos, \& Mortimer, E. F. (2002). Uma análise de pressupostos teóricos da abordagem C-T-S (Ciência-Tecnologia-Sociedade) no contexto da educação brasileira. Ensaio - Pesquisa em Educação em Ciências, 2(2), 110-132. http://dx.doi. org/10.1590/1983-21172000020202

Shamos, M. H. (1995). The myth of scientific literacy. Rutgers University Press.

Silva, K. M. A. (2016). Questões sociocientíficas e o pensamento complexo: tecituras para o Ensino de Ciências. (Tese de Doutorado em Educação). Universidade de Brasília, Brasília.

Silva, S. do N., \& El-Hani, C. N. (2014). A abordagem do tema Ambiente e a formação do cidadão socioambientalmente responsável. Revista Brasileira de Pesquisa em Educação em Ciências, 14(2), 225-234.

Simonneaux, L. (2007). Argumentation in Socio-Scientific Contexts. In S. Erduran, \& M. P. Jiménez-Aleixandre (Orgs.), Argumentation in Science Education: Perspectives from classroom-based research (pp. 179-199). Springer.

Solomon, J., \& Aikenhead, G. (1994). STS education: International perspectives on reform. Teachers College Press. 
Teixeira, P. M. M. (2003). Educação científica e Movimento CTS no quadro das tendências pedagógicas no Brasil. Revista Brasileira de Pesquisa em Educação em Ciências, 3(1), $88-102$.

Torres-Merchán, N. Y., Altuzarra, J. G. C., \& Torres, A. M. (2019). Análise das condições para efetuar a transdisciplinaridade em instituições básicas da educação em Boyacá Colômbia. Educação e Fronteiras, 9(25), 92-109. https://doi.org/10.30612/eduf. v9i25.11014

Vilches, A., Gil-Pérez, D., \& Praia J. (2011). De CTS a CTSA: educação por um futuro sustntável. In W. L. P. Santos, \& D. Auler (Orgs.), CTS e educação científica: Desafios, tendências e resultados de pesquisa (pp. 161-184). Editora Universidade de Brasília.

Zabala, A. (1998). A prática educativa: Como ensinar. Artmed.

Zeidler, D. L., Sadler, T. D., Simmons, M. L., \& Howes, E. V. (2005). Beyond STS: a research-based framework for socioscientific issues education. Science Education, 89, 357-377. https://doi.org/10.1002/sce.20048

Zoller, U. (1991). Teaching/learning styles, performance, and students' teaching evaluation in S/T/E/S-focused Science teacher education. Journal of Research in Science Teaching, 28, 593-607. https://doi.org/10.1002/tea.3660280705

Grégory Alves Dionor

${ }^{\odot}$ https://orcid.org/0000-0003-1933-9664

Universidade Federal da Bahia

Programa de Pós-Graduação em Ensino, Filosofia e História das Ciências

Salvador, Bahia, Brasil

Universidade do Estado da Bahia, Campus $X$

Departamento de Educação

Teixeira de Freitas, Bahia, Brasil

gadionor.bio@gmail.com 
Dália Melissa Conrado

https://orcid.org/0000-0002-7955-2515

Universidade Federal da Grande Dourados

Programa de Pós-Graduação em Educação

Dourados, Mato Grosso do Sul, Brasil

INCT em Estudos Interdisciplinares e Transdisciplinares em

Ecologia e Evolução (IN-TREE)

Bahia, Brasil

profdalia@gmail.com

Liziane Martins

https://orcid.org/0000-0001-8015-4656

Universidade do Estado da Bahia

Campus X, Departamento de Educação

Teixeira de Freitas, Bahia, Brasil

Universidade Federal do Sul da Bahia, Campus Paulo Freire

Instituto de Humanidade Artes e Ciências

Teixeira de Freitas, Bahia, Brasil

lizimartins@gmail.com

Nei de Freitas Nunes-Neto

https://orcid.org/0000-0002-8185-2007

Universidade Federal da Grande Dourados

Faculdade de Ciências Biológicas e Ambientais

Dourados, Mato Grosso do Sul, Brasil

Programa de Pós-Graduação em Ensino, Filosofia e História das Ciências

Salvador, Bahia, Brasil

INCT em Estudos Interdisciplinares e Transdisciplinares em Ecologia e Evolução (IN-TREE)

Bahia, Brasil

nunesneto@gmail.com

Submetido em 17 de dezembro de 2019

Aceito em $\mathbf{2 6}$ de maio de 2020

Publicado em 03 de julho de 2020 